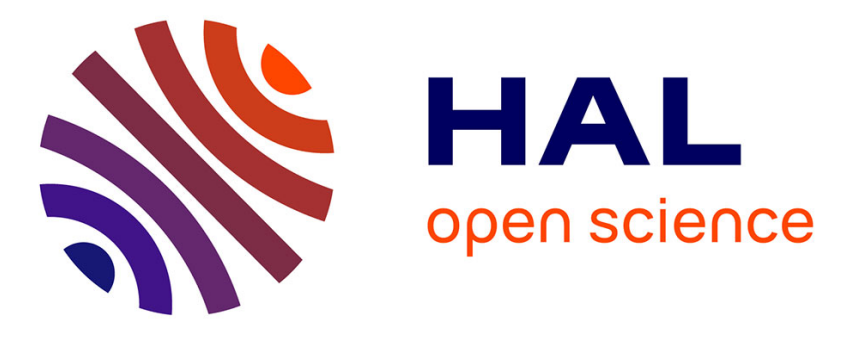

\title{
Soluble CD95L in cancers and chronic inflammatory disorders, a new therapeutic target?
}

Keerthi Kurma, Andrea Boizard-Moracchini, Gael Galli, Mickael Jean, Pierre Vacher, Patrick Blanco, Patrick Legembre

\section{- To cite this version:}

Keerthi Kurma, Andrea Boizard-Moracchini, Gael Galli, Mickael Jean, Pierre Vacher, et al.. Soluble CD95L in cancers and chronic inflammatory disorders, a new therapeutic target?. Biochimica et Biophysica Acta (BBA) - Reviews on Cancer, 2021, 1876 (2), pp.188596. 10.1016/j.bbcan.2021.188596 . hal-03333846

\section{HAL Id: hal-03333846 https://hal.science/hal-03333846}

Submitted on 16 Sep 2021

HAL is a multi-disciplinary open access archive for the deposit and dissemination of scientific research documents, whether they are published or not. The documents may come from teaching and research institutions in France or abroad, or from public or private research centers.
L'archive ouverte pluridisciplinaire HAL, est destinée au dépôt et à la diffusion de documents scientifiques de niveau recherche, publiés ou non, émanant des établissements d'enseignement et de recherche français ou étrangers, des laboratoires publics ou privés. 


\section{Soluble CD95 $\mathrm{L}$ in cancers and chronic inflammatory disorders, a new therapeutic target?}

Keerthi Kurma ${ }^{1}$, Andrea Boizard-Moracchini ${ }^{2}$, Gael Galli ${ }^{2}$, Mickael Jean ${ }^{3}$, Pierre Vacher ${ }^{4}$, Patrick Blanco ${ }^{2}$ and Patrick Legembre ${ }^{1}$.

\section{Authors:}

${ }^{1}$ UMR CNRS 7276, INSERM U1262, CRIBL, Université Limoges, Limoges, France

${ }^{2}$ University of Bordeaux, CNRS, ImmunoConcEpT, UMR 5164, Bordeaux, France

${ }^{3}$ UMR CNRS 6226, ISCR, COrInt, Université de Rennes 1, Rennes, France

${ }^{4}$ INSERM, Centre de Recherche Cardio-Thoracique de Bordeaux, U1045, F-33600 Pessac, France

*Corresponding author: Patrick Legembre, INSERM U1262, CRIBL, Université Limoges, Limoges, France; E-mail: patrick.legembre@inserm.fr

Short title: Pathologies with increased serum CD95L

\section{ACCEPTED MANUSCRIPT}




\begin{abstract}
Although CD95L (also known as FasL) is still predominantly considered as a death ligand that induces apoptosis in infected and transformed cells, substantial evidence indicate that it can also trigger non-apoptotic signaling pathways whose pathophysiological roles remain to be fully elucidated. The transmembrane ligand CD95L belongs to the tumor necrosis factor (TNF) superfamily. After cleavage by metalloprotease, its soluble form (s-CD95L) fails to trigger the apoptotic program but instead induces signaling pathways promoting the aggressiveness of certain inflammatory disorders such as autoimmune diseases and cancers. We propose to evaluate the various pathologies in which the metalloprotease-cleaved CD95L is accumulated and analyze whether this soluble ligand may play a significant role in the pathology progression. Based on the TNF $\alpha$-targeting therapeutics, we envision that targeting the soluble form of CD95L may represent a very attractive therapeutic option in the pathologies depicted herein.
\end{abstract}




\section{Introduction}

CD95 (Fas or APO-1) is undergoing a paradigm change, which could lead to a therapeutic revolution. In addition to its apoptotic function, the death receptor (DR) CD95 can also favor tumor growth and metastasis through the induction of non-apoptotic signaling pathways [1, 2]. In this regard, although the interaction between transmembrane CD95L and CD95 leads to an expected and well-known apoptotic response, which is involved in the elimination of infected and transformed cells [3], the metalloprotease-cleaved CD95L induces multiple nonapoptotic signaling pathways, resulting in chronic inflammation [2, 4-6] and tumor development $[2,7]$. Although CD95L-expressing immune cells including lymphocytes and natural killer (NK) cells infiltrate tumor tissues to kill CD95-expressing cancer cells [3], the loss of CD95 in cancer cells is rarely observed supporting that CD95 might exert oncogenic functions. In this regard, the maintain of CD95 expression by ovarian and liver cancers in mice promotes tumor growth through the constitutive induction of the c-Jun N-terminal Kinase (JNK) signaling pathway [1]. In addition, CD95 participates in the metastatic dissemination of cancer cells [7-10], and contributes to maintain the population of cancer stem cells (CSCs) [11-14]. The CSCs present tumorigenic properties allowing them to replenish the heterogeneous tumor population after an initially successful therapy [15] and thereby, their elimination is crucial to achieving remission. These seminal studies highlight that by inhibiting the CD95-mediated non-apoptotic functions, new generation of drugs could revolutionize the therapy efficiency in these pathologies. Despite the fact that a list of autoimmune, infectious, and cancer diseases with elevated s-CD95L levels was published over fifteen years ago [16], the role of this cytokine in the pathogenesis of these diseases has yet to be elucidated. This review intends to describe the pathologies in which s-CD95L have been found up-regulated and could therefore represent a potential therapeutic target. Associated with this analysis, we will emphasize some of the incorrect conclusions about the CD95/CD95L pair, mainly drawn due to technical issues.

\section{Structure, aggregation level and biological functions of CD95 and CD95L.}

CD95 is a type I transmembrane glycoprotein encompassing 335 amino acids in its premature form (Fig.1), and the removal of its peptide signal engenders a mature protein containing 319 amino acids (Fig.1) [17]. The ligand of CD95, namely CD95L (FasL), is a type II transmembrane protein belonging to the tumor necrosis factor (TNF) family. CD95L exhibits a long intracellular domain, a transmembrane domain, a stalk region, and a Cterminal TNF homology domain (THD) (Fig.2). The long intracellular region of CD95L harbors different motifs, including a tandem casein kinase I phosphorylation site and a proline-rich domain, which serves as a binding site for SH3 (Src homology 3) domaincontaining proteins [18]. Although neglected, the interaction between CD95 and CD95L also induces a "reverse signaling" in the CD95L-bearing cells increasing in the proliferation rate in CD8+ lymphocytes and inducing cell death in CD4+ $\mathrm{T}$ cells $[19,20]$. The bi-directional signaling induced within CD95L- and CD95-expressing cells renders it difficult to draw definitive conclusions from the phenotype of CD95L or CD95 knockout (KO) mice. In other words, the lupus-like phenotype developed by these mice [21] is the consequence of the combined failures to trigger not only the apoptotic and non-apoptotic signaling pathways by CD95, but also the reverse signaling by CD95L rendering difficult to decipher the role of each signal in the pathological phenotype of these mice.

The transmembrane CD95L designated $\mathrm{m}-\mathrm{CD} 95 \mathrm{~L}$ for membrane-CD95L, can be processed within its stalk region (amino acids 102 to 136) by metalloproteases (MMPs) [22]. The soluble extracellular CD95L (s-CD95L) released into the extracellular medium corresponds to 
a homotrimer due to the presence of a trimerization domain in its C-terminal region [23]. Initial studies on s-CD95L suggested that this ligand was neutral in terms of cell signaling and could compete with its membrane-bound counterpart to prevent the implementation of the apoptotic response $[24,25]$. Thus, a homotrimeric CD95L fails to induce apoptosis, while a recombinant hexameric counterpart does [26], indicating that the increase in CD95L stoichiometry exerts a pivotal role in the biological function of the ligand. After cleavage in the cornea, s-CD95L seems to interact with fibronectin within the extracellular matrix to increase in its stoichiometry and retrieve its cytotoxic activity [27]. Interestingly, plasmin can also cleave CD95L between arginine at position 144 and lysine 145 [28], but the soluble ligand seems to preserve its pro-apoptotic activity involved in the elimination of endothelial cells and the inhibition of angiogenesis [28]. In the serum, another form of CD95L exists as a transmembrane ligand present at the surface of exosomes [29]. Many cells can secrete these small extracellular vesicles (20-200 nm), transferring lipids, proteins, and RNAs between cells [30]. These CD95L+ exosomes can be secreted by Epstein-Barr virus (EBV)-infected Bcells [31] or V82 T-cells [32], contributing to kill follicular T cells and dampen the humoral response or to eliminate EBV-associated tumors, respectively. Overall, CD95L is found accumulated in the serum of patients suffering from various diseases and the biological function (i.e., driver or bystander) of this ligand in such pathologies remains to be elucidated. It is important to keep in mind that CD95 is not an enzyme and thereby, to trigger cell signaling, it requires the recruitment of proteases, ubiquitin ligases, kinases or phosphatases through protein-protein interactions (PPIs). In the absence of stimulation, the amino terminal region of CD95, namely pre-ligand assembly domain (PLAD) [33], and the proline motif within its transmembrane domain [34] are responsible for its pre-association as homodimers or homotrimers. The multi-aggregation of CD95 mandatory for the induction of the apoptotic program has been described as a two-step mechanism involving first, a certain degree of CD95 aggregation engendered by its interaction with CD95L and second, the induction of a caspase-8-dependent intracellular signal, promoting the accumulation of unstimulated CD95 into lipid rafts [35] and the induction of the apoptotic signal [36]. The initial CD95-mediated caspase- 8 activation stimulates ceramide production, promoting receptor aggregation and cell death induction [37].

CD95 and CD95L undergo numerous post-translational modifications (PTMs), regulating the downstream signaling pathways. These consist of S-palmitoylation of CD95 at C199 (C194 in mouse CD95) [38, 39], triggering the receptor distribution into lipid rafts and sensitizing reactivated T-cells to cell death [40]. Similarly, S-nitrosylation on both C199 and C304 enhances the distribution of CD95 into lipid rafts and tumor cell death [41]. Sglutathionylation of CD95 at cysteine 294 in mouse is another PTM promoting the receptor aggregation and apoptosis induction [42]. We observed that co-activation of CD95 with both the transmembrane protein CD28 and the glycosylphosphatidylinositol (GPI)-linked factor CD59 induces the CD95 distribution into lipid rafts but these plasma membrane relocalizations affect the induction of cell death contrarily in activated T-cells [43]. This suggests that different types of lipid rafts may exist and affect the initial steps of the death receptor signaling differently.

In patients suffering from acute respiratory distress syndrome (ARDS), s-CD95L undergoes oxidation at methionine 224 and 225, causing its aggregation and promoting its cytotoxic function [44]. Oxidation of methionine at position 121 in CD95L prevents its cleavage by MMP7 and thereby, s-CD95L in ARDS patients preserves its stalk region [44]. Nagata and colleagues previously demonstrated that a recombinant and soluble CD95L encompassing amino acid residues 101 to 279, containing the stalk region, can still induce apoptosis [45]. A recent study confirmed that a soluble CD95L containing the stalk region triggers cell death in the human T-cell line Jurkat and in human small airway epithelial cells [46]. In accordance 
with these findings, conservation of the CD95L stalk region has been shown to promote the efficiency of the CD95/CD95L interaction and the level of s-CD95L aggregation [47], contributing to the release of an apoptotic cytokine. To render the understanding of the biological role of this domain more complex, the amino acid residues 105 to 130 of CD95L can interact with the hepatocyte growth factor (HGF) receptor (also known as c-Met), promoting cell migration of cancer cells in an autocrine fashion [48]. Overall, these findings suggest that both the THD and the juxtamembrane stalk region of CD95L contribute to the ligand multimerization, rendering it difficult to predict the biological function of serum CD95L prior to its sequencing.

\section{A new complex formed upon s-CD95L/CD95 interaction}

CD95 harbors three main intracellular domains, a juxtamembrane calcium inducing domain (CID), a death domain (DD), and a C-terminal region (Fig.1). While the CID and the Cterminal region are involved in implementing non-apoptotic signals, the DD plays a crucial role in the induction of the apoptotic response. The binding of $\mathrm{m}-\mathrm{CD} 95 \mathrm{~L}$ to CD95 induces a homotypic interaction between the DDs of CD95 and Fas-Associated protein with death domain (FADD) (Fig.3). Then, FADD recruits caspases -8 and -10 to trigger the caspase cascade and induce cell death (Fig.3). The CD95/FADD/Caspase complex has been designated DISC for death-inducing signaling complex [49].

Although the homotrimeric s-CD95L fails to form the DISC, this ligand is not neutral and promotes the formation of a different complex that we designated MISC for motility-inducing signaling complex (Fig.3) [6,7]. The main feature of the MISC is the recruitment of the phospholipase C (PLC)- $\gamma 1$ via the interaction of its SH3 domain to the CD95 CID (Fig.1) [5, 50]. It is noteworthy that unlike DD, CID is a disordered structure involved in weak and transient PPIs [4], rendering it difficult to identify its partners. Recruitment of PLC $\gamma 1$ at the plasma membrane catalyzes the cleavage of phosphatidylinositol 4,5-bisphosphate into inositol 1,4,5-trisphosphate (IP3) and diacylglycerol (DAG) acting as second messengers to activate an intracellular calcium $\left(\mathrm{Ca}^{2+}\right)$ response (Fig.3). The CD95-driven IP3 production induces the release of the endoplasmic reticulum (ER)-stored $\mathrm{Ca}^{2+}$ through the stimulation of the IP3 receptors (Fig.3). The increased intracellular $\mathrm{Ca}^{2+}$ concentration is further enhanced by the re-localization of stromal interaction molecule 1 (STIM1) from the ER to the plasma membrane and the opening of the plasma membrane-localized calcium channel ORAI1, creating high and localized calcium spikes, which limit CD95/FADD interaction by activating protein kinase $\mathrm{C}$ (PKC)- $\beta 2$ (Fig.3) [51]. Of note, triple-negative breast cancer (TNBC) cells exposed to s-CD95L also undergo a $\mathrm{Ca}^{2+}$ flux between the endoplasmic reticulum (ER) and the mitochondria, modulating the metabolism of the organelle (i.e., ATP and reactive oxygen species (ROS) productions) and promoting cell migration $[52,53]$.

In addition, MISC contains nicotinamide adenine dinucleotide phosphate (NADPH) oxidase (e.g., Nox3) responsible for ROS production, which activates Src kinases such as c-yes, promoting cell migration in TNBC cells [7]. ROS stimulates Src kinases through the oxidation of cysteine SH groups [54]. The involvement of Src kinases in the CD95-mediated non-apoptotic response has been observed not only in cancer cells $[5,8,9]$ but also in Th17 cells [6] and neutrophils [55]. Nonetheless, the role of Nox and src kinase families in the CD95 signaling pathways remains ambivalent because these enzymes can also participate in the induction of the apoptotic signal in hepatocytes [56], pushing for further investigations to better apprehend the role of ROS and Src kinases in the CD95 signal. Interestingly, src kinases can also recruit tyrosine kinase receptors (TKRs) such as epidermal growth factor receptor (EGFR), thereby connecting CD95 with growth-stimulating effectors $[7,9,10,57$, 58]. Src participates in the phosphoinositide 3-Kinase (PI3K) signaling pathway by the phosphorylation of caspase- 8 , a molecular process that might favor the switch between DISC 
and MISC [59-61]. Indeed, phosphorylation of tyrosine at position 380 in caspase- 8 abrogates the protease activity and generates a binding site for the $\mathrm{SH} 2$ domain of the PI3K subunit $\mathrm{p} 85$ and the subsequent activation of the PI3K/Akt signaling pathway [59-61]. This CD95mediated PI3K/Akt signaling pathway is essential in cancer cell migration [7, 10]. Taken together, these studies demonstrate that CD95-mediated, and in particular s-CD95L-mediated non-apoptotic signaling can induce cell migration.

\section{S-CD95L and Cancer}

The s-CD95L expression has been found to be increased in several cancers and chronic inflammatory disorders since its discovery $[24,25]$, with biological functions ranging from pro-apoptotic to pro-inflammatory ligand (Fig.4). Although most studies on CD95L have focused on its apoptotic function and thus its putative role in the elimination of tumorinfiltrating immune cells by cancer cells ("tumor counterattack" theory [62]) or its failure to induce the immune contraction in autoimmune disorders, more recent evidence emphasize that the non-apoptotic and pro-inflammatory functions of s-CD95L could also affect the progression of these pathologies. To identify the cancers in which novel drugs targeting CD95/CD95L pair could represent attractive therapeutic options, we describe the pathologies in which the concentration of s-CD95L has been investigated.

\section{Hematological malignancies}

s-CD95L has been initially detected up-regulated in sera from patients affected with natural killer-large granular lymphocyte (NK-LGL) leukemia, T-LGL leukemia, and NK-lymphoma [63]. In contrast, no trace of this ligand has been found in adult T-cell leukemia (ATL), acute myelogenous leukemia (AML), acute promyelocytic leukemia (APL) or acute lymphocytic leukemia (ALL) [63]. Contradicting this initial study, a prospective analysis on childhood lymphoproliferative malignancies, including 18 ALLs and 7 non-Hodgkin lymphomas (NHLs) patients revealed a significant increase in s-CD95L concentration [64]. Moreover, patients with elevated s-CD95L levels exhibited a detrimental effect on relapse-free survival (RFS) and overall survival (OS) [64]. This discrepancy could be explained by the cancer stage and also by the comparison of patients at diagnosis or in the course of the treatment. Indeed, a follow-up of NK lymphoma patients treated with CHOP protocol (a chemotherapeutic regimen including cyclophosphamide, hydroxydaunorubicin, oncovin and prednisolone) revealed that this treatment not only reduced the number of lymphoma cells but also decreased in serum CD95L concentration [63].

In multiple myeloma (MM), the concentration of s-CD95L was higher than that in control subjects and increased with the disease progression [65]. Although the CD95L-expressing cells have yet to be identified in this cancer, the quantity of this ligand in MM patients serum was correlated with that of interleukin-6 (IL-6), a pro-inflammatory cytokine associated with MM oncogenesis, and s-CD95L seemed to favor bone marrow infiltration via an unknown mechanism that needs to be elucidated [65].

\section{Solid tumors}

\section{Gastro-intestinal cancers}

The concentration of s-CD95L has been found increased in colon cancer patients' sera as compared to that in healthy donors [66]. Furthermore, supernatants of cultured colon cancer cells containing s-CD95L induced apoptosis of CD95-sensitive cells, while supernatants without s-CD95L did not [66]. Interestingly, serum CD95L levels dropped after tumor resection suggesting that the tumor or its environment was the main source of s-CD95L, but 
further investigations are needed to identify these CD95L-expressing cells. In contrast to this study, additional experiments on colon cancer cell lines observed CD95L transcription and translation but did not detect the presence of CD95L at the plasma membrane [67], and colon cancer cells did not kill CD95-sensitive immune cells [67].

To explain this discrepancy, it is noteworthy that most of the initial analyses involving tumor cells as the primary source of CD95L were carried out using anti-CD95L antibodies, which turned out to be unspecific in immunohistochemistry (IHC) and flow cytometry experiments rendering uncertain the conclusion of these studies [68]. In agreement with these data, a study evaluating the selectivity of twelve anti-CD95L antibodies confirmed that the polyclonal antibodies N20 and C20 from Santa Cruz and the monoclonal clone 33 from Transduction Laboratory displayed unspecific staining using flow cytometry and IHC methods [69]. On the other hand, anti-CD95L monoclonal antibodies (mAbs) designated G247-4 and NOK-1 showed strong selectivity for human CD95L $[62,70]$.

Pancreatic carcinoma patients expressed higher levels of s-CD95L as compared to healthy subjects, and this concentration increased with the pathology aggressiveness [71]. Unfortunately, the CD95L staining performed by IHC in this latter study also relied on unspecific mAbs, rendering difficult to apprehend the source of CD95L in this tumor.

Hepatocellular carcinoma (HCC) also exhibited some plasma membrane CD95L, but as aforementioned, the IHC was performed with unspecific polyclonal anti-CD95L antibodies (i.e., C20 from Santa Cruz) [69]. Interestingly, the authors observed that these tumors expressed a splicing variant of CD95 rendering it soluble, allowing them not only to block the CD95L/CD95 interaction but also to reduce the quantity of transmembrane CD95 in these tumor cells [72], a cellular process associated with inhibition of oncogenesis [1]. Infection with Hepatitis $\mathrm{C}$ virus (HCV) can result in cirrhosis and $\mathrm{HCC}$, and an interesting gradient of s-CD95L concentration has been reported between healthy subjects, HCV-infected patients, and $\mathrm{HCV}$-infected patients with $\mathrm{HCC}$, suggesting that s-CD95L accumulation could be a noninvasive marker of the disease progression to cancer [73].

In stomach carcinoma, although the concentrations of serum CD95L were significantly different as compared to those in healthy donors [74], this cytokine was accumulated later in the disease progression. Interestingly, the quantity of s-CD95L was correlated with the metastatic dissemination of the pathology, and patients with high levels exhibited a worse prognosis than those with low levels, signifying that this cytokine could exert a pro-metastatic activity in this pathology [74].

\section{Central nervous system cancers}

Although s-CD95L was increased in the cyst fluids of astrocytomas, it only contributed to a minor part (11.4\%) of the cell death signal observed in the CD95-sensitive Jurkat T-cell line exposed to these fluids [75], suggesting that this ligand could exert other biological functions in this pathology. In an ocular tumor model, the metalloprotease-cleaved CD95L promoted the metastatic dissemination of cancer cells by recruiting neutrophils suggesting that s-CD95L could act as an inflammatory and pro-metastatic cytokine [76].

\section{Sarcoma}

In Ewing's sarcoma, membrane-bound CD95L was detected and associated with the metastatic dissemination of these tumors [77]. This ligand was cleaved by unidentified metalloproteases, releasing a soluble ligand that accumulated in this pathology. Even though the anti-CD95L G247-2 mAb was used in this study, the authors only used it for western 
blotting and not for IHC analyses rendering it difficult to conclude from their IHC results showing CD95L staining in cancer cells. It is also worth noting that the authors had to concentrate supernatants by 15 to achieve $24 \%$ of cell death in the CD95-sensitive Jurkat Tcells. Since protein concentration promotes unnatural CD95L aggregation, favoring its cytotoxic activity [78], the apoptotic role of s-CD95L in this pathology remains doubtful. On the other hand, as recently reported, this metalloprotease-cleaved CD95L could exert a promigration effect on these tumors [7-9].

\section{Breast cancers}

Breast cancer cells express less CD95 than normal surrounding tissues and, despite the fact that immune cells, endothelial cells, and cancer cells seem to express CD95L in tumor tissues, these cells remained sensitive to the CD95-mediated apoptotic signal, implying that the reduction of CD95 expression was associated with a different function than resistance to cell death [79]. Moreover, the anti-CD95L antibody used in IHC images was not detailed rendering it difficult to determine the staining specificity. Because the mix of breast cancer cells with CD95-sensitive cells triggered a trivial apoptotic response, we could conclude from this study that either CD95L was not expressed by these cancer cells or CD95L exerted a nonapoptotic function at the surface of these cells [79].

Breast cancer is a heterogeneous disease with a molecular classification allowing to distinguish between the luminal $\mathrm{A}$ and $\mathrm{B}$ expressing hormonal receptors including estrogen and/or progesterone receptors (PR), basal/TNBC, and human epidermal growth factor receptor 2 (HER2)-overexpressing tumors [80]. Basal/TNBC patients show the poorest clinical outcomes, and no targeted therapies exist compared to other molecular subtypes. We observed that serum CD95L concentration was increased among TNBC women compared to that in healthy subjects, and this was associated with an increased risk of relapse. This ligand was a potent chemoattractant for TNBC cell lines [7], suggesting that s-CD95L could promote metastatic dissemination in these women. Moreover, we established that CD95L was ectopically expressed by neo-vessels in the tumors [7]. These findings suggest that inhibition of the CD95-mediated signal and more accurately, the inhibition of the non-apoptotic signaling pathways might represent a novel and attractive therapeutic option in this pathology in which it exists an urgent therapeutic need.

\section{Gynecologic cancers}

\section{Ovary}

In an initial study on ovarian cancers, despite the use of a non-selective anti-CD95L mAb for IHC experiments [81], the authors observed that a highly glycosylated CD95L was expressed in the endolysosomal organelles of the ovarian cancers cells. These CD95L-containing microvesicles were secreted and detected in the ascites of ovarian cancer patients. Hence, CD95L-expressing exosomes triggered apoptosis in CD95-sensitive T-cells, suggesting that it could have an immunosuppressive effect in this pathology [81]. Besides that, we recently established that the serum concentration of s-CD95L is increased in women with advanced high-grade serous ovarian cancer (HGSOC) as compared to healthy women [82]. In contrast to TNBC [7], higher levels of this ligand were associated with a good prognosis and with increased tumor-infiltrating $\mathrm{T}-\left(\mathrm{CD}^{+}\right.$and $\left.\mathrm{CD}^{+}\right)$and B-lymphocytes [82]. Interestingly, similar to TNBCs, endothelial cells covering newly formed blood vessels inside the tumor expressed transmembrane CD95L [82].

\section{Uterus}

s-CD95L was also increased in the serum of women affected by uterine tumors compared to healthy controls [83]. The concentration of s-CD95L increased with the clinical stages of the 
disease, suggesting that in this pathology, s-CD95L could exert an oncogenic effect [83] and therapeutic regimens targeting this cytokine might be of interest to treat these women.

\section{Prostate cancers}

Liu et al. demonstrated that prostate cancer cell lines (i.e., LNCaP, DU145, and PC3 cells) expressed CD95L and secreted a cleaved ligand, but NOK-1 or G247-4 clone was not used in this study, rendering these findings questionable [84]. Nonetheless, the authors observed that elevated concentrations of serum MMP-7, a metalloprotease involved in the CD95L cleavage [85], were associated with poor prognosis in prostate cancer patients [86].

\section{Melanoma}

Although soluble CD95L was not significantly up-regulated in melanoma patients, the only two stage IV patients with distant metastases in this cohort showed an increased amount of sCD95L as compared to healthy subjects [87], suggesting again that s-CD95L did not play a pivotal role in the primary tumor growth but could exert a pro-metastatic function. The putative pro-metastatic role of s-CD95L has been confirmed by another study [88]. Of note, some melanoma cells have been reported to degranulate CD95L-expressing exosomes that could exert a cytotoxic activity [89].

\section{Head and Neck cancers}

s-CD95L concentration has been found increased in patients with laryngeal squamous cell carcinoma as compared to healthy donors, and the surgical treatment applied to these patients engendered a drop of the soluble cytokine concentration, indicating that s-CD95L stemmed from the primary tumor. However, the CD95L-expressing cells in the tumor tissue remains to be identified [90].

While oral squamous cell carcinoma showed no increase in s-CD95L when compared to healthy subjects [91], another study performed with head and neck cancers exhibited a significant reduction in s-CD95L compared to healthy subjects, indicating a different regulation of this ligand in these pathologies [92].

\section{Thyroid cancer}

Similar to HGSOC [82], high levels of s-CD95L in thyroid cancer patients were associated with disease-free survival [93]. Plasminogen activator inhibitor-1 (PAI-1) inhibits plasmin activity [94]. As aforementioned, DeClerck et al. observed that PAI-1 expression by endothelial cells protected angiogenesis from a CD95L-mediated apoptotic program in neuroblastoma tumors [28]. By blocking the plasmin activity, PAI-1 inhibited the release of a soluble and cytotoxic CD95L from the surface of endothelial cells [28]. Unexpectedly, both PAI-1 and s-CD95L were associated with progression-free survival in thyroid cancers, suggesting that the combination of these markers as a prognostic factor cannot be generalized.

\section{Lung cancers}

No variation of serum levels of s-CD95L in malignant (lung cancer patients) or tuberculous pleurisy patients were detected compared to healthy donors, regardless the fact that the values depicted in the manuscript were in the $\mu \mathrm{g} / \mathrm{mL}$ range, far higher than the concentrations in the other cancers which were in $\mathrm{ng} / \mathrm{mL}$ [95]. Interestingly, serum MMP7 concentration was also associated with poor survival in patients with non-small-cell lung cancer treated with cisplatin-based chemotherapy [96].

Overall, these studies indicate that although the concentration of s-CD95L seems to be up(i.e., colon, pancreas, liver, stomach, breast with the triple-negative breast cancer, uterus, 
prostate, melanoma, larynx, and sarcoma) or down- (i.e., ovary, thyroid) regulated in cancers, its role in the pathology progression necessitates further investigations. In addition, the presence of the MMP-cleaved CD95L raises the question of the identification of the CD95Lexpressing cells and the metalloprotease(s) involved in the shedding process using validated tools. Finally, the high concentrations of s-CD95L in certain cancers suggest that drugs targeting the CD95/CD95L pair could represent potential therapeutic options for these patients.

\section{S-CD95L and chronic inflammatory disorders}

\section{Multiple sclerosis}

Multiple sclerosis (MS) is an autoimmune disease targeting the central nervous system. In MS, the immune system damages myelin engendering deterioration of the nerves. Of note, CD95 stimulation can induce the production of inflammatory cytokines, which are involved in the activation and recruitment of innate immune cells such as neutrophils and macrophages. To do so, CD95 engagement relies on different mechanisms including the induction of a caspase-dependent apoptotic program in monocytes and macrophages [97, 98], although this receptor can also promote an inflammatory program in a caspase-independent manner in macrophages [98]. Combined with TNF, CD95L can trigger the caspase-1 activation and the production of the pro-inflammatory IL1 $\beta$ via a caspase-8-dependent mechanism in antigenpresenting cells such as macrophages or dendritic cells [99]. This CD95L-mediated IL1 $\beta$ production is responsible for the pathological progression in experimental autoimmune encephalomyelitis (EAE), a mouse model of multiple sclerosis (MS). In this study, CD95 deficient (lpr mice) and non-functional CD95L-expressing mice ( $g l d$ mice) resisted to a myelin oligodendrocyte glycoprotein (MOG) model of EAE [100]. Because the concentration of s-CD95L is not up-regulated in the sera of MS patients, we may consider that the transmembrane CD95L contributes to this pathology [101].

\section{Lupus and Sjögren's syndrome}

Lupus and Sjögren's syndrome (SS) are systemic autoimmune disorders. While in Sjögren's syndrome, the immune system targets mainly salivary and tear glands engendering dryness in the eyes and mouth, these diseases can affect other organs including skin, kidneys, articulations, lungs, and brain. In Lupus and SS, accumulating evidence points to s-CD95L as a pivotal effector of the disease aggressiveness [6,102], with a recent study confirming that sCD95L levels were higher in lupus patients [103]. We previously observed that s-CD95L concentrations were associated with the disease progression in lupus patients, and that this ligand promoted the Th17 trafficking in inflamed organs $[4,5]$. We generated a cell-permeant peptide based on the CID sequence that prevented the CD95/PLC $\gamma 1$ interaction and thereby, selectively inhibited the non-apoptotic signaling pathway [5]. Injection of this peptide alleviated clinical symptoms in lupus-prone mice. Finally, to improve the pharmacokinetic properties of this drug, we switched the peptide structure to that of a protease-resistant peptidomimetic (i.e., an AApeptide designated DB550) and confirmed the therapeutic value of this novel generation of CD95-targeting drugs [4]. Interestingly, CD95 stimulation could also promote Th17-driven inflammatory pathologies via its role in Th17 cell differentiation [104]. Indeed, a comprehensive analysis of the regulatory network controlling the differentiation of mouse Th17 cells revealed CD95 as a key factor [105], capable of sequestering signal transducer and activator of transcription (STAT1), thus promoting STAT3 transcriptomic activity [104]. Beyond s-CD95L, membrane-bound CD95L may also play a role in lupus inflammation, as CD95L expressing Th1 cells $\left(\mathrm{Tbet}^{+}\right)$were involved in the severity of cutaneous lupus erythematosus (CLE) in a Toll like receptor 9 (TLR9)-KO murine 
model [106]. These CD95L+ Th1 T-cells induced the synthesis of inflammatory chemokines such as IL-1, IL-6, CXCL2 or CXCL1 known to mediate skin lesions by interacting with CD95+ cells, which could be keratinocytes or skin-infiltrating myeloid CD11b+ cells [106]. Interestingly, knock-in mice in which the wild type CD95L was replaced by its soluble counterpart developed more aggressive lupus as compared to that observed in CD95L-KO mice and died to kidney damage and histiocytic sarcoma cancer suggesting that the presence of s-CD95L could aggravate the auto-immune pathology and promote oncogenesis [2]. Nonetheless, we cannot rule out that this aggressiveness was due to the lack of "reverse signaling", this question must be addressed in the future.

Initial studies in SS patients showed a significant increase in s-CD95L as compared to healthy donors, and more interestingly, the concentration of this ligand dropped after steroid therapy (prednisolone or methylprednisolone), indicating that s-CD95L dosage in humans must be performed using samples from patients at the diagnosis [107].

\section{Ocular pathologies}

Nabel et al. highlighted that grafts of CD95L-expressing colon carcinoma cells were eliminated faster than those of wild type tumors because CD95L promoted the recruitment of neutrophils and the induction of a robust inflammatory program [108]. Because of the presence of TGF- $\beta$, this difference was lost when tumors were grafted into the anterior chamber of the eye [108]. Because Marshak-Rothstein and colleagues have recently described the role of CD95L in ocular pathologies [109], we will not go into further details.

\section{Rheumatoid arthritis (RA)}

Rheumatoid arthritis is a systemic disease and the most frequent form of chronic arthritis. In addition to affect articulations, RA also exhibits a variety of extra-articular manifestations. In Rheumatoid arthritis patients, s-CD95L was found to be elevated in the synovial fluid (SF) and was associated with the pathology's aggressiveness, despite serum levels of s-CD95L being comparable to those dosed in healthy subjects. Another study using sera from RA patients, as well as insulin-dependent diabetes mellitus, systemic lupus erythematosus, gastric cancer, and leukemia patients observed a significant increase in s-CD95L in these pathologies [110], rendering it difficult to conclude whether s-CD95L was only up-regulated in SF or in both SF and sera of RA patients. Moreover, s-CD95L concentration in SF was found increased in RA patients as compared to that in osteoarthritis patients and correlated to the knee joint score, a disease progression marker [111]. Of note, in this pathology, MMP1, MMP2, MMP-8 and MMP9 failed to cleave membrane-bound CD95L, whereas MMP3 and MMP7 did. Additionally, the observed correlation between s-CD95L and MMP3 concentrations suggested that this metalloprotease could be responsible for the accumulation of the soluble form of CD95L in RA patients. However, as the authors failed to quantify MMP7 in SF of RA patients, we cannot rule out the possibility that MMP7 was also involved in the cleavage of CD95L in these pathology [111]. Overall, it remains to address how sCD95L could contribute to the pathology progression in RA patients.

\section{Familial Mediterranean fever (FMF)}

FMF is a monogenic inflammatory disease caused by mutations in the MEditerranean FeVer (MEFV) gene encoding pyrin $[112,113]$. These mutations cause recurrent episodes of fever and serositis. Although the genetic aspect of this pathology is well described, the pathogenesis of inflammatory flares remains poorly understood. Ceri et al. reported no significant increase in serum s-CD95L levels in FMF patients versus controls, and s-CD95L concentrations did not vary between attack and attack-free periods [114], suggesting that s-CD95L do not exert any effect in this pathology. 


\section{Psoriasis}

Psoriasis is a chronic skin disease that progresses in a cyclic fashion, with flare up and remission. This chronic inflammatory disease is characterized by immune cell infiltration and psoriatic keratinocytes resistant to apoptosis. Although, the concentration of s-CD95L in the sera of psoriasis patients did not vary compared to that in healthy subjects, it increased in patients undergoing Goeckerman therapy [115], a daily dermal application of crude coal tar containing polycyclic aromatic hydrocarbons (PAH), combined with exposure to ultraviolet radiation (UVR) or a topical treatment of dithranol [116]. Unfortunately, the role of s-CD95L in treatment efficiency was not investigated in these studies.

\section{Atherosclerosis}

Atherosclerosis is a systemic inflammatory disease mediated by several factors and often associated with hypertension. Okura et al. wondered whether s-CD95L levels could be elevated in atherosclerosis patients, in which transmembrane CD95L was detected on endothelial cells and MMPs were found to be over-expressed [117]. Interestingly, the endothelial dysfunction in atherosclerosis, measured by the intima-media thickness in the carotid artery, was correlated with the s-CD95L concentration [117]. In agreement with this pioneering study, a positive correlation between s-CD95L and atherosclerotic lesions was confirmed in a second analysis [118], suggesting that the release of membrane-bound CD95L by metalloproteases could represent a robust and non-invasive biological marker for severe coronary artery diseases. Nonetheless, no molecular or cellular mechanism has been proposed to rationalize this correlation.

\section{Toxic epidermal necrolysis (TEN) and Stevens-Johnson syndrome (SJS)}

TEN and SJS are severe blistering diseases associated with keratinocyte apoptosis in the epidermis, which results in dermo-epidermal separation and bullae. s-CD95L was found upregulated in TEN and SJS patient's sera compared to healthy subjects [119]. In this pathology, s-CD95L could exert a cytotoxic activity on keratinocytes via a molecular mechanism that remains to be elucidated $[119,120]$. If s-CD95L kills keratinocytes through induction of apoptosis, we hypothesize that s-CD95L aggregation may be increased in these pathologies by an oxidative process such as the one described in ARDS patients [121].

\section{Hashimoto's Thyroiditis (HT) and Graves disease}

Graves' disease and chronic thyroiditis (also designated Hashimoto's thyroiditis) are autoimmune diseases targeting the thyroid gland. While the Graves' disease is caused by the stimulation of the thyroid-stimulating hormone (TSH, or thyrotropin) receptor promoting the hyperplasia of the thyroid gland, patients affected by Hashimoto's thyroiditis undergo a reduction of the TSH hormone activity leading to the organ atrophy. Some connections exist between these two pathologies since certain patients suffering from Hashimoto's disease have been diagnosed following the treatment of Graves' disease episode [122].

Carla Giordano and colleagues reported that thyrocytes from HT glands expressed CD95 while healthy thyrocytes did not [123]. This group also observed the expression of CD95L at the mRNA and protein levels in normal and HT thyrocytes, and suggested that because normal thyrocytes did not express CD95, the thyroid damage only occurred in the HT patients. However, using similar methods and antibodies, another group failed to confirm these findings [68]. Questioning the conclusion from the former study, a technical note evaluating the selectivity of commercial anti-CD95L antibodies revealed that the two antiCD95L antibodies used in HT studies (i.e., the monoclonal clone 33 from Transduction 
Laboratories and the rabbit polyclonal IgG C-20, from Santa Cruz Biotechnology) were unspecific [69].

Although it remains to address whether thyroid glands express the transmembrane CD95L, sCD95L has been found increased in sera of patients affected by Graves' hyperthyroidism as compared to those of Graves' disease in remission and s-CD95L concentration was correlated with the concentration of a disease marker, namely the anti-TSH receptor antibodies (TRAb) [124].

Overall, these studies on chronic inflammatory disorders suggest that s-CD95L could exert a potent pro-inflammatory activity that could contribute to the aggressivity of these pathologies. Accordingly, we hypothesize that small drugs or antibodies inhibiting selectively the proinflammatory signal induced by s-CD95L could alleviate clinical symptoms in the diseases exhibiting elevated serum concentrations of s-CD95L.

\section{S-CD95L and infections}

Initial studies on s-CD95L showed that it is up-regulated in patients infected with Plasmodium falciparum malaria [125], tuberculosis [126], and human immunodeficiency virus (HIV) [127]. We recently confirmed that s-CD95L levels were elevated in HIV patients [4]. Interestingly, increased s-CD95L concentration was associated with lymphopenia in malaria patients, which the authors hypothesized, was caused by the CD95L apoptotic function. Soluble CD95L was reported accumulated in sera of hepatitis B virus patients [128], while a Korean cohort of patients exhibited an opposite trend [129], rendering it difficult to conclude for the presence of this ligand in this infection.

\section{7. s-CD95L and transplantation}

Acute graft-versus-host disease ( $\mathrm{aG} v \mathrm{HD})$ is a major complication associated with allogeneic bone marrow transplantation (BMT). During the preparative stage and the period of myelosuppression, serum s-CD95L concentrations drop and then increase with hematopoietic reconstitution after BMT. Moreover, sera of patients with aGvHD exhibit higher CD95L concentrations than those without aGvHD [130]. Unexpectedly, administration of s-CD95L to $\mathrm{BALB} / \mathrm{c}$ mice receiving C57BL/6 strain transplant (graft skin) extended the survival time of grafted mice. According to this study, s-CD95L induced graft tolerance in mouse models by decreasing IL-2 and IFN- $\gamma$ expressions while increasing IL-4 expression [131]. These findings render it difficult to apprehend the role of $\mathrm{s}-\mathrm{CD} 95 \mathrm{~L}$ in $\mathrm{aG} v \mathrm{HD}$ and would require further investigations.

It has also been reported that activated T cells were more susceptible to CD95-mediated apoptosis than naive counterparts because CD95 redistribution into lipid rafts in activated $\mathrm{T}$ cells rendered these cells more prone to re-stimulation [132]. Accordingly, ex vivo incubation of T cells with agonistic anti-CD95 mAb (Jo2 clone) or a recombinant and cytotoxic CD95L selectively deleted alloreactive T-cells, while sparing the graft versus tumor $(\mathrm{G} v \mathrm{~T}) \mathrm{T}$ cell response [133]. The GvHD inhibition initially attributed to the elimination of alloreactive $\mathrm{T}$ cells could be, in fact, caused by the expression of CD95L by memory T-cells. Indeed, the presence of these CD95L-expressing memory $\mathrm{T}$ cells during adoptive cell transfer (ACT), to treat patients with advanced cancer, accelerated the conversion of the naive $\mathrm{T}$ cells into differentiated memory effector cells through a CD95-mediated PI3K signaling [134]. This accelerated conversion of naive T cells reduced their anti-tumor capacity during ACT and was designated "precocious differentiation", a biological process that could synchronize the immune response and terminate it. 


\section{8. s-CD95L and aging}

Few studies have analyzed the concentration of s-CD95L in relation to age. Werner's syndrome is a typical progeroid syndrome manifesting a variety of age-related symptoms, which have been shown to be associated with chronic inflammation. Interestingly, the concentration of s-CD95L in healthy subjects is strongly correlated with natural aging and this ligand is found to be increased in Werner's syndrome patients [135]. Although the pathophysiologic role of serum CD95L in aging is not elucidated, its pro-inflammatory functions in neutrophils [55, 108] and Th17 cells $[4,5,105]$ or its role in "precocious differentiation" could contribute to aging.

\section{Natural inhibitors of CD95/CD95L interaction}

DcR3 is a TNFR member, lacking transmembrane and intracellular sequences. DcR3 interacts with CD95L [136], and genomic amplification of this soluble receptor has been reported in approximately half of the lung and colon cancers [136], as well as its overexpression has been demonstrated in $44 \%$ of gastrointestinal cancers [137]. Although DcR3 mRNA was found to be highly expressed in pancreatic cancer cells, the expression level of this soluble protein was not associated with clinical markers rendering it difficult to confirm a putative role of this factor in the pathology progression [138].

Several forms of soluble CD95 (sCD95) are derived from alternative splicing phenomena [139], and soluble CD95 was found increased in sera of silicosis patients and systemic lupus erythematosus patients [140]. These spliced variants of CD95 conserve their amino-terminal oligomerization domain, termed PLAD [33], allowing them to interact with wild-type CD95 [141] and thereby dominantly interfere with the downstream signaling pathway by generating non-functional homodimers or trimers. Some of these soluble forms of CD95 can still interact with CD95L and prevent its interaction with wild-type CD95, acting as a decoy receptor [142]. The major CD95 spliced variant is devoid of its exon 6 (i.e., encoding for TM domain) (Fig.1) and corresponds to a soluble receptor that can interact with transmembrane CD95L and by doing so, triggers a CD95L-induced "reverse signaling" leading to cell death [143] and rendering complex the evaluation of its pathophysiologic role. Of note, the heterozygous expression of an exon 6-spliced CD95 gene should also engender a reduction of the CD95 level at the plasma membrane (the remaining wild type allele). It is noteworthy that the loss of plasma membrane CD95 leads to the inhibition of tumor growth in different tumor cells [1]. Similarly, the presence of CD95 in lung adenocarcinomas can exert protection against tyrosine kinase inhibitors by evoking a yet uncharacterized NFkB signal that contributes to tumor relapse [144]. We recently observed that the genetic loss of CD95 in TNBC cells reduced tumor growth by releasing an immune checkpoint on NK cells [145]. Accordingly, CD95 loss in TNBC cells triggered a CD95L-independent inflammatory transcriptomic signature modulating the immune landscape in these breast cancers [145].

The reduction or the loss of the transmembrane CD95 is also observed in ALPS patients type 0 (ALPS-FAS in the revised classification) [146] and in Lpr mice [147, 148] leading to lupuslike disorder.

\section{Concluding remarks}

Three decades after the cloning of CD95 [17], although the CD95-induced apoptosis is crucial for the elimination of infected and transformed cells or the immune contraction [3], the role of 
its non-apoptotic functions has been overlooked, and we are only beginning to understand the molecular mechanisms underlying the induction of these responses.

The dichotomous role of CD95 reflects the development of drugs with either antagonist or agonist properties. APO010 is a CD95 agonist that mimics hexameric CD95L whose administration prolonged the survival of glioma-bearing mice [149]. The short peptide residue YLGA designated Met12, disrupts CD95 homotrimerization [150], inhibiting the induction of both the apoptotic and non-apoptotic responses. In a rat model of age-related macular degeneration, intravenous injection of Met12 significantly reduced retinal degeneration [151]. Strategies for targeting the CD95L/CD95 system are similar to those used for the TNF system, with Asunercept (APG101), a CD95 decoy receptor, which is currently tested in phase I clinical trial of myelodysplastic syndrome (MDS), and in a phase II trial of glioma showing a beneficial progression-free survival for patients treated with a combination of radiotherapy and APG101 as compared to radiotherapy alone [152]. Based on the pivotal role of the CD95-mediated apoptotic signal in the anti-tumor and anti-infectious responses, as well as in the immune homeostasis, we can envision that chronic administration of Asunercept in patients might lead to unwanted effects such as chronic infection, autoimmune symptoms or oncogenesis which might be circumvented with the generation of novel drugs specifically inhibiting the non-apoptotic signaling pathways of CD95. As such, we recently demonstrated that targeting CD95 non-apoptotic signaling is pharmacologically achievable and therapeutically beneficial in a pre-clinical model of lupus [4]. If these chemical derivatives might be useful in other s-CD95L- and Th17-driven pathologies remains to be evaluated. In addition, aforementioned cancer and inflammatory disorders, in which elevated concentrations of s-CD95L are detected push us to compare the therapeutic value of large spectrum inhibitors, including neutralizing antibodies or decoy receptors targeting CD95/CD95L pair with that of more selective inhibitors such as DB550 [4] abrogating the CD95-mediated non-apoptotic signal. Further unraveling the PPIs required for the apoptotic and non-apoptotic cellular functions of CD95 at the level of the CD95-associated complex and defining the precise forms of s-CD95L that accumulate in various pathologic conditions, will also likely prove therapeutically meaningful in the context of both autoimmune diseases and cancers. 


\section{References}

[1] L. Chen, S.M. Park, A.V. Tumanov, A. Hau, K. Sawada, C. Feig, J.R. Turner, Y.X. Fu, I.L. Romero, E. Lengyel, M.E. Peter, CD95 promotes tumour growth, Nature 465(7297) (2010) 492-6.

[2] L.A. O' Reilly, L. Tai, L. Lee, E.A. Kruse, S. Grabow, W.D. Fairlie, N.M. Haynes, D.M. Tarlinton, J.G. Zhang, G.T. Belz, M.J. Smyth, P. Bouillet, L. Robb, A. Strasser, Membranebound Fas ligand only is essential for Fas-induced apoptosis, Nature 461(7264) (2009) 65963.

[3] A. Strasser, P.J. Jost, S. Nagata, The many roles of FAS receptor signaling in the immune system, Immunity 30(2) (2009) 180-92.

[4] A. Poissonnier, J.P. Guegan, H.T. Nguyen, D. Best, N. Levoin, G. Kozlov, K. Gehring, R. Pineau, F. Jouan, L. Morere, S. Martin, M. Thomas, E. Lazaro, I. Douchet, T. Ducret, P. van de Weghe, P. Blanco, M. Jean, P. Vacher, P. Legembre, Disrupting the CD95-PLCgamma1 interaction prevents Th17-driven inflammation, Nat Chem Biol 14(12) (2018) 1079-1089. [5] A. Poissonnier, D. Sanseau, M. Le Gallo, M. Malleter, N. Levoin, R. Viel, L. Morere, A. Penna, P. Blanco, A. Dupuy, F. Poizeau, A. Fautrel, J. Seneschal, F. Jouan, J. Ritz, E. Forcade, N. Rioux, C. Contin-Bordes, T. Ducret, A.M. Vacher, P.A. Barrow, R.J. Flynn, P. Vacher, P. Legembre, CD95-Mediated Calcium Signaling Promotes T Helper 17 Trafficking to Inflamed Organs in Lupus-Prone Mice, Immunity 45(1) (2016) 209-23.

[6] S. Tauzin, B. Chaigne-Delalande, E. Selva, N. Khadra, S. Daburon, C. Contin-Bordes, P. Blanco, J. Le Seyec, T. Ducret, L. Counillon, J.F. Moreau, P. Hofman, P. Vacher, P. Legembre, The naturally processed CD95L elicits a c-yes/calcium/PI3K-driven cell migration pathway, PLoS Biol 9(6) (2011) e1001090.

[7] M. Malleter, S. Tauzin, A. Bessede, R. Castellano, A. Goubard, F. Godey, J. Leveque, P. Jezequel, L. Campion, M. Campone, T. Ducret, G. MacGrogan, L. Debure, Y. Collette, P. Vacher, P. Legembre, CD95L cell surface cleavage triggers a prometastatic signaling pathway in triple-negative breast cancer, Cancer Res 73(22) (2013) 6711-21.

[8] F.J. Hoogwater, M.W. Nijkamp, N. Smakman, E.J. Steller, B.L. Emmink, B.F. Westendorp, D.A. Raats, M.R. Sprick, U. Schaefer, W.J. Van Houdt, M.T. De Bruijn, R.C. Schackmann, P.W. Derksen, J.P. Medema, H. Walczak, I.H. Borel Rinkes, O. Kranenburg, Oncogenic K-Ras turns death receptors into metastasis-promoting receptors in human and mouse colorectal cancer cells, Gastroenterology 138(7) (2010) 2357-67.

[9] S. Kleber, I. Sancho-Martinez, B. Wiestler, A. Beisel, C. Gieffers, O. Hill, M. Thiemann, W. Mueller, J. Sykora, A. Kuhn, N. SchregImann, E. Letellier, C. Zuliani, S. Klussmann, M.

Teodorczyk, H.J. Grone, T.M. Ganten, H. Sultmann, J. Tuttenberg, A. von Deimling, A. Regnier-Vigouroux, C. Herold-Mende, A. Martin-Villalba, Yes and PI3K bind CD95 to signal invasion of glioblastoma, Cancer Cell 13(3) (2008) 235-48.

[10] M. Teodorczyk, S. Kleber, D. Wollny, J.P. Sefrin, B. Aykut, A. Mateos, P. Herhaus, I.

Sancho-Martinez, O. Hill, C. Gieffers, J. Sykora, W. Weichert, C. Eisen, A. Trumpp, M.R. Sprick, F. Bergmann, T. Welsch, A. Martin-Villalba, CD95 promotes metastatic spread via Sck in pancreatic ductal adenocarcinoma, Cell Death Differ 22(7) (2015) 1192-202.

[11] P. Ceppi, A. Hadji, F.J. Kohlhapp, A. Pattanayak, A. Hau, X. Liu, H. Liu, A.E. Murmann, M.E. Peter, CD95 and CD95L promote and protect cancer stem cells, Nat Commun 5 (2014) 5238.

[12] M. Drachsler, S. Kleber, A. Mateos, K. Volk, N. Mohr, S. Chen, B. Cirovic, J. Tuttenberg, C. Gieffers, J. Sykora, C.R. Wirtz, W. Mueller, M. Synowitz, A. Martin-Villalba, CD95 maintains 
stem cell-like and non-classical EMT programs in primary human glioblastoma cells, Cell Death Dis 7 (2016) e2209.

[13] A.S. Qadir, P. Ceppi, S. Brockway, C. Law, L. Mu, N.N. Khodarev, J. Kim, J.C. Zhao, W. Putzbach, A.E. Murmann, Z. Chen, W. Chen, X. Liu, A.R. Salomon, H. Liu, R.R. Weichselbaum, J. Yu, M.E. Peter, CD95/Fas Increases Stemness in Cancer Cells by Inducing a STAT1Dependent Type I Interferon Response, Cell reports 18(10) (2017) 2373-2386.

[14] A.S. Qadir, A.M. Stults, A.E. Murmann, M.E. Peter, The mechanism of how CD95/Fas activates the Type I IFN/STAT1 axis, driving cancer stemness in breast cancer, Sci Rep 10(1) (2020) 1310.

[15] J. Chen, Y. Li, T.S. Yu, R.M. McKay, D.K. Burns, S.G. Kernie, L.F. Parada, A restricted cell population propagates glioblastoma growth after chemotherapy, Nature 488(7412) (2012) 522-6.

[16] A. Linkermann, J. Qian, M. Lettau, D. Kabelitz, O. Janssen, Considering Fas ligand as a target for therapy, Expert Opin Ther Targets 9(1) (2005) 119-34.

[17] N. Itoh, S. Yonehara, A. Ishii, M. Yonehara, S.-I. Mizushima, M. Sameshima, A. Hase, Y. Seto, S. Nagata, The polypeptide encoded by the cDNA for human cell surface antigen Fas can mediate apoptosis, Cell 66(2) (1991) 233-243.

[18] K. Luckerath, V. Kirkin, I.M. Melzer, F.B. Thalheimer, D. Siele, W. Milani, T. Adler, A. Aguilar-Pimentel, M. Horsch, G. Michel, J. Beckers, D.H. Busch, M. Ollert, V. Gailus-Durner, H. Fuchs, M. Hrabe de Angelis, F.J. Staal, K. Rajalingam, A.O. Hueber, L.J. Strobl, U. ZimberStrobl, M. Zornig, Immune modulation by Fas ligand reverse signaling: lymphocyte proliferation is attenuated by the intracellular Fas ligand domain, Blood 117(2) (2011) 51929.

[19] J. Desbarats, R.C. Duke, M.K. Newell, Newly discovered role for Fas ligand in the cellcycle arrest of CD4+ T cells, Nat Med 4(12) (1998) 1377-82.

[20] I. Suzuki, P.J. Fink, Maximal proliferation of cytotoxic T lymphocytes requires reverse signaling through Fas ligand, J Exp Med 187(1) (1998) 123-8.

[21] S. Nagata, T. Suda, Fas and Fas ligand: Ipr and gld mutations, Immunol Today 16(1) (1995) 39-43.

[22] J.P. Guegan, P. Legembre, Nonapoptotic functions of Fas/CD95 in the immune response, FEBS J 285(5) (2018) 809-827.

[23] M. Tanaka, T. Itai, M. Adachi, S. Nagata, Downregulation of Fas ligand by shedding, Nat Med 4(1) (1998) 31-6.

[24] P. Schneider, N. Holler, J.L. Bodmer, M. Hahne, K. Frei, A. Fontana, J. Tschopp, Conversion of membrane-bound Fas(CD95) ligand to its soluble form is associated with downregulation of its proapoptotic activity and loss of liver toxicity, J Exp Med 187(8) (1998) 1205-13.

[25] T. Suda, H. Hashimoto, M. Tanaka, T. Ochi, S. Nagata, Membrane Fas ligand kills human peripheral blood T lymphocytes, and soluble Fas ligand blocks the killing, J Exp Med 186(12) (1997) 2045-50.

[26] N. Holler, A. Tardivel, M. Kovacsovics-Bankowski, S. Hertig, O. Gaide, F. Martinon, A. Tinel, D. Deperthes, S. Calderara, T. Schulthess, J. Engel, P. Schneider, J. Tschopp, Two adjacent trimeric Fas ligands are required for Fas signaling and formation of a death-inducing signaling complex, Mol Cell Biol 23(4) (2003) 1428-40.

[27] K. Aoki, M. Kurooka, J.J. Chen, J. Petryniak, E.G. Nabel, G.J. Nabel, Extracellular matrix interacts with soluble CD95L: retention and enhancement of cytotoxicity, Nat Immunol 2(4) (2001) 333-7. 
[28] K. Bajou, H. Peng, W.E. Laug, C. Maillard, A. Noel, J.M. Foidart, J.A. Martial, Y.A. DeClerck, Plasminogen activator inhibitor-1 protects endothelial cells from FasL-mediated apoptosis, Cancer Cell 14(4) (2008) 324-34.

[29] R. Alonso, M.C. Rodriguez, J. Pindado, E. Merino, I. Merida, M. Izquierdo, Diacylglycerol kinase alpha regulates the secretion of lethal exosomes bearing Fas ligand during activationinduced cell death of T lymphocytes, J Biol Chem 280(31) (2005) 28439-50.

[30] G. Raposo, W. Stoorvogel, Extracellular vesicles: exosomes, microvesicles, and friends, J Cell Biol 200(4) (2013) 373-83.

[31] S.K. Lundy, S.H. Taitano, L. van der Vlugt, Characterization and Activation of Fas LigandProducing Mouse B Cells and Their Killer Exosomes, Methods Mol Biol 2270 (2021) 149-178. [32] X. Wang, Z. Xiang, Y. Liu, C. Huang, Y. Pei, X. Wang, H. Zhi, W.H. Wong, H. Wei, I.O. Ng, P.P. Lee, G.C. Chan, Y.L. Lau, W. Tu, Exosomes derived from Vdelta2-T cells control EpsteinBarr virus-associated tumors and induce T cell antitumor immunity, Sci Transl Med 12(563) (2020).

[33] R.M. Siegel, J.K. Frederiksen, D.A. Zacharias, F.K.-M. Chan, M. Johnson, D. Lynch, R.Y. Tsien, M.J. Lenardo, Fas Preassociation Required for Apoptosis Signaling and Dominant Inhibition by Pathogenic Mutations, Science 288(5475) (2000) 2354-2357.

[34] Q. Fu, T.M. Fu, A.C. Cruz, P. Sengupta, S.K. Thomas, S. Wang, R.M. Siegel, H. Wu, J.J. Chou, Structural Basis and Functional Role of Intramembrane Trimerization of the Fas/CD95 Death Receptor, Mol Cell 61(4) (2016) 602-613.

[35] D. Siegmund, I. Lang, H. Wajant, Cell death-independent activities of the death receptors CD95, TRAILR1, and TRAILR2, FEBS J 284(8) (2017) 1131-1159.

[36] C. Gajate, E. Del Canto-Janez, A.U. Acuna, F. Amat-Guerri, E. Geijo, A.M. Santos-Beneit, R.J. Veldman, F. Mollinedo, Intracellular triggering of Fas aggregation and recruitment of apoptotic molecules into Fas-enriched rafts in selective tumor cell apoptosis, J Exp Med 200(3) (2004) 353-65.

[37] H. Grassme, A. Cremesti, R. Kolesnick, E. Gulbins, Ceramide-mediated clustering is required for CD95-DISC formation, Oncogene 22(35) (2003) 5457-70.

[38] K. Chakrabandhu, Z. Herincs, S. Huault, B. Dost, L. Peng, F. Conchonaud, D. Marguet, H.T. He, A.O. Hueber, Palmitoylation is required for efficient Fas cell death signaling, Embo J 26(1) (2007) 209-20.

[39] C. Feig, V. Tchikov, S. Schutze, M.E. Peter, Palmitoylation of CD95 facilitates formation of SDS-stable receptor aggregates that initiate apoptosis signaling, Embo J 26(1) (2007) 22131.

[40] A.C. Cruz, M. Ramaswamy, C. Ouyang, C.A. Klebanoff, P. Sengupta, T.N. Yamamoto, F. Meylan, S.K. Thomas, N. Richoz, R. Eil, S. Price, R. Casellas, V.K. Rao, J. Lippincott-Schwartz, N.P. Restifo, R.M. Siegel, Fas/CD95 prevents autoimmunity independently of lipid raft localization and efficient apoptosis induction, Nat Commun 7 (2016) 13895.

[41] L. Leon-Bollotte, S. Subramaniam, O. Cauvard, S. Plenchette-Colas, C. Paul, C. Godard, A. Martinez-Ruiz, P. Legembre, J.F. Jeannin, A. Bettaieb, S-nitrosylation of the death receptor fas promotes fas ligand-mediated apoptosis in cancer cells, Gastroenterology 140(7) (2011) 2009-18, 2018 e1-4.

[42] V. Anathy, S.W. Aesif, A.S. Guala, M. Havermans, N.L. Reynaert, Y.S. Ho, R.C. Budd, Y.M. Janssen-Heininger, Redox amplification of apoptosis by caspase-dependent cleavage of glutaredoxin 1 and S-glutathionylation of Fas, J Cell Biol 184(2) (2009) 241-52.

[43] P. Legembre, S. Daburon, P. Moreau, J.F. Moreau, J.L. Taupin, Modulation of Fasmediated apoptosis by lipid rafts in T lymphocytes, J Immunol 176(2) (2006) 716-20. 
[44] R. Herrero, O. Kajikawa, G. Matute-Bello, Y. Wang, N. Hagimoto, S. Mongovin, V. Wong, D.R. Park, N. Brot, J.W. Heinecke, H. Rosen, R.B. Goodman, X. Fu, T.R. Martin, The biological activity of FasL in human and mouse lungs is determined by the structure of its stalk region, The Journal of clinical investigation 121(3) (2011) 1174-90.

[45] T. Suda, M. Tanaka, K. Miwa, S. Nagata, Apoptosis of mouse naive T cells induced by recombinant soluble Fas ligand and activation-induced resistance to Fas ligand, J Immunol 157(9) (1996) 3918-24.

[46] O. Kajikawa, R. Herrero, Y.H. Chow, C.F. Hung, G. Matute-Bello, The bioactivity of soluble Fas ligand is modulated by key amino acids of its stalk region, PLoS One 16(6) (2021) e0253260.

[47] D. Berg, M. Lehne, N. Muller, D. Siegmund, S. Munkel, W. Sebald, K. Pfizenmaier, H. Wajant, Enforced covalent trimerization increases the activity of the TNF ligand family members TRAIL and CD95L, Cell Death Differ 14(12) (2007) 2021-34.

[48] H.C. Lin, P.Y. Lai, Y.P. Lin, J.Y. Huang, B.C. Yang, Fas ligand enhances malignant behavior of tumor cells through interaction with Met, hepatocyte growth factor receptor, in lipid rafts, J Biol Chem 287(24) (2012) 20664-73.

[49] C. Scaffidi, S. Fulda, A. Srinivasan, C. Friesen, F. Li, K.J. Tomaselli, K.M. Debatin, P.H. Krammer, M.E. Peter, Two CD95 (APO-1/Fas) signaling pathways, Embo J 17(6) (1998) 167587.

[50] H.T. Nguyen, J.P. Guegan, D. Best, P. van de Weghe, N. Levoin, P. Legembre, M. Jean, Probing the side chain tolerance for inhibitors of the CD95/PLCgamma1 interaction, Bioorg Med Chem Lett (2019) 126669.

[51] N. Khadra, L. Bresson-Bepoldin, A. Penna, B. Chaigne-Delalande, B. Segui, T. Levade, A.M. Vacher, J. Reiffers, T. Ducret, J.F. Moreau, M.D. Cahalan, P. Vacher, P. Legembre, CD95 triggers Orai1-mediated localized Ca2+ entry, regulates recruitment of protein kinase $C$ (PKC) beta2, and prevents death-inducing signaling complex formation, Proc Natl Acad Sci U S A 108(47) (2011) 19072-7.

[52] M. Bessou, J. Lopez, R. Gadet, M. Deygas, N. Popgeorgiev, D. Poncet, A. Nougarede, P. Billard, I. Mikaelian, P. Gonzalo, R. Rimokh, G. Gillet, The apoptosis inhibitor Bcl-xL controls breast cancer cell migration through mitochondria-dependent reactive oxygen species production, Oncogene (2020).

[53] A. Fouque, E. Lepvrier, L. Debure, Y. Gouriou, M. Malleter, V. Delcroix, M. Ovize, T. Ducret, C. Li, M. Hammadi, P. Vacher, P. Legembre, The apoptotic members CD95, BclxL, and $\mathrm{Bcl}-2$ cooperate to promote cell migration by inducing $\mathrm{Ca}(2+)$ flux from the endoplasmic reticulum to mitochondria, Cell Death Differ 23(10) (2016) 1702-16.

[54] E. Giannoni, F. Buricchi, G. Raugei, G. Ramponi, P. Chiarugi, Intracellular reactive oxygen species activate Src tyrosine kinase during cell adhesion and anchorage-dependent cell growth, Mol Cell Biol 25(15) (2005) 6391-403.

[55] L. Gao, G.S. Gulculer, L. Golbach, H. Block, A. Zarbock, A. Martin-Villalba, Endothelial cell-derived CD95 ligand serves as a chemokine in induction of neutrophil slow rolling and adhesion, Elife 5 (2016).

[56] R. Reinehr, S. Becker, A. Eberle, S. Grether-Beck, D. Haussinger, Involvement of NADPH oxidase isoforms and Src family kinases in CD95-dependent hepatocyte apoptosis, J Biol Chem 280(29) (2005) 27179-94.

[57] F.J. Hoogwater, E.J. Steller, B.F. Westendorp, I.H. Borel Rinkes, O. Kranenburg, CD95 signaling in colorectal cancer, Biochim Biophys Acta 1826(1) (2012) 189-98. 
[58] E. Letellier, S. Kumar, I. Sancho-Martinez, S. Krauth, A. Funke-Kaiser, S. Laudenklos, K. Konecki, S. Klussmann, N.S. Corsini, S. Kleber, N. Drost, A. Neumann, M. Levi-Strauss, B. Brors, N. Gretz, L. Edler, C. Fischer, O. Hill, M. Thiemann, B. Biglari, S. Karray, A. MartinVillalba, CD95-ligand on peripheral myeloid cells activates Syk kinase to trigger their recruitment to the inflammatory site, Immunity 32(2) (2010) 240-52.

[59] S. Cursi, A. Rufini, V. Stagni, I. Condo, V. Matafora, A. Bachi, A.P. Bonifazi, L. Coppola, G. Superti-Furga, R. Testi, D. Barila, Src kinase phosphorylates Caspase-8 on Tyr380: a novel mechanism of apoptosis suppression, EMBO J 25(9) (2006) 1895-905.

[60] J. Senft, B. Helfer, S.M. Frisch, Caspase-8 interacts with the p85 subunit of phosphatidylinositol 3-kinase to regulate cell adhesion and motility, Cancer Res 67(24) (2007) 11505-9.

[61] I.R. Powley, M.A. Hughes, K. Cain, M. MacFarlane, Caspase-8 tyrosine-380 phosphorylation inhibits CD95 DISC function by preventing procaspase- 8 maturation and cycling within the complex, Oncogene 35(43) (2016) 5629-5640.

[62] N.P. Restifo, Countering the 'counterattack' hypothesis, Nat Med 7(3) (2001) 259. [63] M. Tanaka, T. Suda, K. Haze, N. Nakamura, K. Sato, F. Kimura, K. Motoyoshi, M. Mizuki, S. Tagawa, S. Ohga, K. Hatake, A.H. Drummond, S. Nagata, Fas ligand in human serum, Nat Med 2(3) (1996) 317-22.

[64] V. Hazar, Z. Berber, E. Pestereli, M. Coskun, A. Yesilipek, G. Karpuzoglu, O. Yegin, Clinical importance of circulating and cellular expression levels of Fas and Fas ligand in pediatric patients with lymphoproliferative malignancies, Pediatr Hematol Oncol 22(3) (2005) 247-56. [65] M.G. Alexandrakis, C.A. Pappa, A. Kolovou, S. Kyriakaki, R. Vyzoukaki, M. Devetzoglou, G. Tsirakis, Circulating levels of soluble Fas ligand reflect disease progression in multiple myeloma, Med Oncol 31(5) (2014) 953.

[66] E. Song, J. Chen, N. Ouyang, F. Su, M. Wang, U. Heemann, Soluble Fas ligand released by colon adenocarcinoma cells induces host lymphocyte apoptosis: an active mode of immune evasion in colon cancer, Br J Cancer 85(7) (2001) 1047-54.

[67] N. Favre-Felix, A. Fromentin, A. Hammann, E. Solary, F. Martin, B. Bonnotte, Cutting edge: the tumor counterattack hypothesis revisited: colon cancer cells do not induce T cell apoptosis via the Fas (CD95, APO-1) pathway, J Immunol 164(10) (2000) 5023-7.

[68] T.A. Stokes, M. Rymaszewski, P.L. Arscott, S.H. Wang, J.D. Bretz, J. Bartron, J.R. Baker, Constitutive Expression of FasL in Thyrocytes, Science 279(5359) (1998) 2015-2015.

[69] J. Strater, H. Walczak, C. Hasel, I. Melzner, F. Leithauser, P. Moller, CD95 ligand (CD95L) immunohistochemistry: a critical study on 12 antibodies, Cell Death Differ 8(3) (2001) 273-8. [70] N.P. Restifo, Not so Fas: Re-evaluating the mechanisms of immune privilege and tumor escape, Nat Med 6(5) (2000) 493-5.

[71] G. Bellone, C. Smirne, A. Carbone, K. Mareschi, L. Dughera, E.C. Farina, O. Alabiso, G. Valente, G. Emanuelli, U. Rodeck, Production and pro-apoptotic activity of soluble CD95 ligand in pancreatic carcinoma, Clinical cancer research 6(6) (2000) 2448-55.

[72] S.H. Lee, M.S. Shin, H.S. Lee, J.H. Bae, H.K. Lee, H.S. Kim, S.Y. Kim, J.J. Jang, M. Joo, Y.K. Kang, W.S. Park, J.Y. Park, R.R. Oh, S.Y. Han, J.H. Lee, S.H. Kim, J.Y. Lee, N.J. Yoo, Expression of Fas and Fas-related molecules in human hepatocellular carcinoma, Hum Pathol 32(3) (2001) 250-6.

[73] M. El-Mesery, M. El-Mowafy, A. Elgaml, L.F. Youssef, S.Y. Abed, Correlation of Serum Soluble Fibrinogen-Like Protein 2 with Soluble FAS Ligand and Interferon Gamma in Egyptian Hepatitis C Virus-Infected Patients and Hepatocellular Carcinoma Patients, J Interferon Cytokine Res 37(8) (2017) 342-347. 
[74] S. Tsutsumi, H. Kuwano, T. Shimura, N. Morinaga, E. Mochiki, T. Asao, Circulating soluble Fas ligand in patients with gastric carcinoma, Cancer 89(12) (2000) 2560-4.

[75] B. Frankel, S.L. Longo, G.W. Canute, Soluble Fas-ligand (sFasL) in human astrocytoma cyst fluid is cytotoxic to T-cells: another potential means of immune evasion, J Neurooncol 48(1) (2000) 21-6.

[76] M.S. Gregory, R.R. Saff, A. Marshak-Rothstein, B.R. Ksander, Control of ocular tumor growth and metastatic spread by soluble and membrane Fas ligand, Cancer Res 67(24) (2007) 11951-8.

[77] N. Mitsiades, V. Poulaki, V. Kotoula, A. Leone, M. Tsokos, Fas ligand is present in tumors of the Ewing's sarcoma family and is cleaved into a soluble form by a metalloproteinase, Am J Pathol 153(6) (1998) 1947-56.

[78] N. Holler, A. Tardivel, M. Kovacsovics-Bankowski, S. Hertig, O. Gaide, A. Tinel, D. Deperthes, S. Calderara, T. Schulthess, J. Engel, P. Schneider, J. Tschopp, Two adjacent trimeric Fas ligands are required for Fas signaling and formation of a death-inducing signaling complex, Mol Cell Biol 23(4) (2003) 1428-40.

[79] L. Mullauer, I. Mosberger, M. Grusch, M. Rudas, A. Chott, Fas ligand is expressed in normal breast epithelial cells and is frequently up-regulated in breast cancer, J Pathol 190(1) (2000) 20-30.

[80] C.E. DeSantis, S.A. Fedewa, A. Goding Sauer, J.L. Kramer, R.A. Smith, A. Jemal, Breast cancer statistics, 2015: Convergence of incidence rates between black and white women, $C A$ Cancer J Clin 66(1) (2016) 31-42.

[81] V.M. Abrahams, S.L. Straszewski, M. Kamsteeg, B. Hanczaruk, P.E. Schwartz, T.J. Rutherford, G. Mor, Epithelial ovarian cancer cells secrete functional Fas ligand, Cancer Res 63(17) (2003) 5573-81.

[82] T. de La Motte Rouge, J. Corne, A. Cauchois, M. Le Boulch, C. Poupon, S. Henno, N. Rioux-Leclercq, E. Le Pabic, B. Laviolle, V. Catros, J. Leveque, A. Fautrel, M. Le Gallo, P. Legembre, V. Lavoue, Serum CD95L level correlates with tumor immune infiltration and is a positive prognostic marker for advanced high grade serous ovarian cancer, Mol Cancer Res (2019).

[83] Z. Kondera-Anasz, A. Mielczarek-Palacz, J. Sikora, Soluble Fas receptor and soluble Fas ligand in the serum of women with uterine tumors, Apoptosis 10(5) (2005) 1143-9.

[84] Q.Y. Liu, M.A. Rubin, C. Omene, S. Lederman, C.A. Stein, Fas ligand is constitutively secreted by prostate cancer cells in vitro, Clin Cancer Res 4(7) (1998) 1803-11.

[85] T. Vargo-Gogola, H.C. Crawford, B. Fingleton, L.M. Matrisian, Identification of novel matrix metalloproteinase-7 (matrilysin) cleavage sites in murine and human Fas ligand, Arch Biochem Biophys 408(2) (2002) 155-61.

[86] T. Szarvas, M. Becker, F. Vom Dorp, J. Meschede, A. Scherag, A. Bankfalvi, H. Reis, K.W. Schmid, I. Romics, H. Rubben, S. Ergun, Elevated serum matrix metalloproteinase 7 levels predict poor prognosis after radical prostatectomy, Int J Cancer 128(6) (2011) 1486-92. [87] G. Melzani, G. Bugari, G. Parrinello, G. Mori, A. Manganoni, G. De Panfilis, Evaluation of soluble Fas ligand as a serological marker for melanoma, Dermatology 205(2) (2002) 111-5. [88] P. Redondo, T. Solano, V.A. B, A. Bauza, M. Idoate, Fas and Fas ligand: expression and soluble circulating levels in cutaneous malignant melanoma, Br J Dermatol 147(1) (2002) 806.

[89] G. Andreola, L. Rivoltini, C. Castelli, V. Huber, P. Perego, P. Deho, P. Squarcina, P. Accornero, F. Lozupone, L. Lugini, A. Stringaro, A. Molinari, G. Arancia, M. Gentile, G. 
Parmiani, S. Fais, Induction of lymphocyte apoptosis by tumor cell secretion of FasL-bearing microvesicles, J Exp Med 195(10) (2002) 1303-16.

[90] L. Pignataro, E. Arisi, G. Sambataro, M.M. Corsi, Soluble Fas (sFas) and soluble Fas ligand (sFas-L) balance in laryngeal carcinoma before and after surgical treatment, J Surg Oncol 83(2) (2003) 112-5.

[91] J.S. Zepeda-Nuno, C. Guerrero-Velazquez, S. Del Toro-Arreola, N. Vega-Magana, J. Angeles-Sanchez, J. Haramati, A.L. Pereira-Suarez, M.R. Bueno-Topete, Expression of ADAM10, Fas, FasL and Soluble FasL in Patients with Oral Squamous Cell Carcinoma (OSCC) and their Association with Clinical-Pathological Parameters, Pathol Oncol Res 23(2) (2017) 345-353.

[92] C.T. Chiu, P.W. Wang, M. Asare-Werehene, B.K. Tsang, D.B. Shieh, Circulating Plasma Gelsolin: A Predictor of Favorable Clinical Outcomes in Head and Neck Cancer and Sensitive Biomarker for Early Disease Diagnosis Combined with Soluble Fas Ligand, Cancers (Basel) 12(6) (2020).

[93] T.K. Owonikoko, M.S. Hossain, C. Bhimani, Z. Chen, S. Kim, S.S. Ramalingam, S.Y. Sun, D.M. Shin, E.K. Waller, F.R. Khuri, Soluble FAS ligand as a biomarker of disease recurrence in differentiated thyroid cancer, Cancer 119(8) (2013) 1503-11.

[94] D.A. Waltz, L.R. Natkin, R.M. Fujita, Y. Wei, H.A. Chapman, Plasmin and plasminogen activator inhibitor type 1 promote cellular motility by regulating the interaction between the urokinase receptor and vitronectin, J Clin Invest 100(1) (1997) 58-67.

[95] H.Y. Cui, Q. Zhang, B. Su, W. Li, S.J. Tang, Differential levels of cytokines and soluble Fas ligand between tuberculous and malignant effusions, J Int Med Res 38(6) (2010) 2063-9.

[96] N. Mitsiades, W.H. Yu, V. Poulaki, M. Tsokos, I. Stamenkovic, Matrix metalloproteinase7-mediated cleavage of Fas ligand protects tumor cells from chemotherapeutic drug cytotoxicity, Cancer Res 61(2) (2001) 577-81.

[97] A.M. Hohlbaum, M.S. Gregory, S.T. Ju, A. Marshak-Rothstein, Fas ligand engagement of resident peritoneal macrophages in vivo induces apoptosis and the production of neutrophil chemotactic factors, J Immunol 167(11) (2001) 6217-24.

[98] D.R. Park, A.R. Thomsen, C.W. Frevert, U. Pham, S.J. Skerrett, P.A. Kiener, W.C. Liles, Fas (CD95) induces proinflammatory cytokine responses by human monocytes and monocytederived macrophages, J Immunol 170(12) (2003) 6209-16.

[99] A. Jain, R.A. Irizarry-Caro, M.M. McDaniel, A.S. Chawla, K.R. Carroll, G.R. Overcast, N.H. Philip, A. Oberst, A.V. Chervonsky, J.D. Katz, C. Pasare, T cells instruct myeloid cells to produce inflammasome-independent IL-1beta and cause autoimmunity, Nat Immunol 21(1) (2020) 65-74.

[100] H. Waldner, R.A. Sobel, E. Howard, V.K. Kuchroo, Fas- and FasL-deficient mice are resistant to induction of autoimmune encephalomyelitis, J Immunol 159(7) (1997) 3100-3. [101] M. Moreno, M. Saenz-Cuesta, J. Castillo, E. Canto, L. Negrotto, A. Vidal-Jordana, X. Montalban, M. Comabella, Circulating levels of soluble apoptosis-related molecules in patients with multiple sclerosis, J Neuroimmunol 263(1-2) (2013) 152-4.

[102] E. Tinazzi, A. Puccetti, R. Gerli, A. Rigo, P. Migliorini, S. Simeoni, R. Beri, M. Dolcino, N. Martinelli, R. Corrocher, C. Lunardi, Serum DNase I, soluble Fas/FasL levels and cell surface Fas expression in patients with SLE: a possible explanation for the lack of efficacy of hrDNase I treatment, Int Immunol 21(3) (2009) 237-43.

[103] F.B. Vincent, R. Kandane-Rathnayake, R. Koelmeyer, J. Harris, A.Y. Hoi, F. Mackay, E.F. Morand, Associations of serum soluble Fas and Fas ligand (FasL) with outcomes in systemic lupus erythematosus, Lupus Sci Med 7(1) (2020). 
[104] G. Meyer Zu Horste, D. Przybylski, M.A. Schramm, C. Wang, A. Schnell, Y. Lee, R. Sobel, A. Regev, V.K. Kuchroo, Fas Promotes T Helper 17 Cell Differentiation and Inhibits T Helper 1 Cell Development by Binding and Sequestering Transcription Factor STAT1, Immunity 48(3) (2018) 556-569 e7.

[105] N. Yosef, A.K. Shalek, J.T. Gaublomme, H. Jin, Y. Lee, A. Awasthi, C. Wu, K. Karwacz, S. Xiao, M. Jorgolli, D. Gennert, R. Satija, A. Shakya, D.Y. Lu, J.J. Trombetta, M.R. Pillai, P.J. Ratcliffe, M.L. Coleman, M. Bix, D. Tantin, H. Park, V.K. Kuchroo, A. Regev, Dynamic regulatory network controlling TH17 cell differentiation, Nature 496(7446) (2013) 461-8. [106] P. Mande, B. Zirak, W.C. Ko, K. Taravati, K.L. Bride, T.Y. Brodeur, A. Deng, K. Dresser, Z. Jiang, R. Ettinger, K.A. Fitzgerald, M.D. Rosenblum, J.E. Harris, A. Marshak-Rothstein, Fas ligand promotes an inducible TLR-dependent model of cutaneous lupus-like inflammation, J Clin Invest 128(7) (2018) 2966-2978.

[107] H. Hashimoto, M. Tanaka, T. Suda, T. Tomita, K. Hayashida, E. Takeuchi, M. Kaneko, H. Takano, S. Nagata, T. Ochi, Soluble Fas ligand in the joints of patients with rheumatoid arthritis and osteoarthritis, Arthritis Rheum 41(4) (1998) 657-62.

[108] J.J. Chen, Y. Sun, G.J. Nabel, Regulation of the proinflammatory effects of Fas ligand (CD95L), Science 282(5394) (1998) 1714-7.

[109] M. Gregory-Ksander, A. Marshak-Rothstein, The FasLane to ocular pathologymetalloproteinase cleavage of membrane-bound FasL determines FasL function, J Leukoc Biol (2021).

[110] N.L. Li, H. Nie, Q.W. Yu, J.Y. Zhang, A.L. Ma, B.H. Shen, L. Wang, J. Bai, X.H. Chen, T. Zhou, D.Q. Zhang, Role of soluble Fas ligand in autoimmune diseases, World J Gastroenterol 10(21) (2004) 3151-6.

[111] H. Matsuno, K. Yudoh, Y. Watanabe, F. Nakazawa, H. Aono, T. Kimura, Stromelysin-1 (MMP-3) in synovial fluid of patients with rheumatoid arthritis has potential to cleave membrane bound Fas ligand, J Rheumatol 28(1) (2001) 22-8.

[112] Ancient missense mutations in a new member of the RoRet gene family are likely to cause familial Mediterranean fever. The International FMF Consortium, Cell 90(4) (1997) 797-807.

[113] F.M.F.C. French, A candidate gene for familial Mediterranean fever, Nat Genet 17(1) (1997) 25-31.

[114] M. Ceri, S. Unverdi, M. Senes, M. Altay, R. Yilmaz, D. Yucel, M. Duranay, Serum soluble fas ligand levels in familial Mediterranean fever, Ren Fail 35(6) (2013) 835-7.

[115] L. Borska, C. Andrys, J. Krejsek, K. Hamakova, J. Kremlacek, V. Palicka, D. Ranna, Z. Fiala, Genotoxic and apoptotic effects of Goeckerman therapy for psoriasis, Int J Dermatol 49(3) (2010) 289-94.

[116] H. Mysliwiec, A. Baran, P. Mysliwiec, M. Gorska, I. Flisiak, Upregulation of the sFas/sFasL system in psoriatic patients, Adv Med Sci 60(1) (2015) 64-8.

[117] T. Okura, S. Watanabe, Y. Jiang, M. Nakamura, Y. Takata, Z.H. Yang, K. Kohara, Y. Kitami, K. Hiwada, Soluble Fas ligand and atherosclerosis in hypertensive patients, J Hypertens 20(5) (2002) 895-8.

[118] A. Sahinarslan, B. Boyaci, S.A. Kocaman, S. Topal, U. Ercin, K. Okyay, N. Bukan, R. Yalcin, A. Cengel, The Relationship of Serum Soluble Fas Ligand (sFasL) Level with the Extent of Coronary Artery Disease, Int J Angiol 21(1) (2012) 29-34.

[119] R. Abe, T. Shimizu, A. Shibaki, H. Nakamura, H. Watanabe, H. Shimizu, Toxic epidermal necrolysis and Stevens-Johnson syndrome are induced by soluble Fas ligand, Am J Pathol 162(5) (2003) 1515-20. 
[120] I. Viard, P. Wehrli, R. Bullani, P. Schneider, N. Holler, D. Salomon, T. Hunziker, J.H. Saurat, J. Tschopp, L.E. French, Inhibition of toxic epidermal necrolysis by blockade of CD95 with human intravenous immunoglobulin, Science 282(5388) (1998) 490-3.

[121] R. Herrero, O. Kajikawa, G. Matute-Bello, Y. Wang, N. Hagimoto, S. Mongovin, V. Wong, D.R. Park, N. Brot, J.W. Heinecke, H. Rosen, R.B. Goodman, X. Fu, T.R. Martin, The biological activity of FasL in human and mouse lungs is determined by the structure of its stalk region, J Clin Invest 121(3) (2011) 1174-90.

[122] H. Umar, N. Muallima, J.M. Adam, H. Sanusi, Hashimoto's thyroiditis following Graves' disease, Acta Med Indones 42(1) (2010) 31-5.

[123] C. Giordano, G. Stassi, R. De Maria, M. Todaro, P. Richiusa, G. Papoff, G. Ruberti, M. Bagnasco, R. Testi, A. Galluzzo, Potential involvement of Fas and its ligand in the pathogenesis of Hashimoto's thyroiditis, Science 275(5302) (1997) 960-3.

[124] C.Y. Wang, W.B. Zhong, T.C. Chang, Y.F. Tsai, Circulating soluble Fas ligand correlates with disease activity in Graves' hyperthyroidism, Metabolism 51(6) (2002) 769-73.

[125] P. Kern, M. Dietrich, C. Hemmer, N. Wellinghausen, Increased levels of soluble Fas ligand in serum in Plasmodium falciparum malaria, Infect Immun 68(5) (2000) 3061-3.

[126] T. Mustafa, S.J. Mogga, S.G. Mfinanga, O. Morkve, L. Sviland, Significance of Fas and Fas ligand in tuberculous lymphadenitis, Immunology 114(2) (2005) 255-62.

[127] N. Hosaka, N. Oyaizu, M.H. Kaplan, H. Yagita, S. Pahwa, Membrane and soluble forms of Fas (CD95) and Fas ligand in peripheral blood mononuclear cells and in plasma from human immunodeficiency virus-infected persons, J Infect Dis 178(4) (1998) 1030-9.

[128] M.T.M. Shata, E.A. Abdel-Hameed, S.D. Rouster, L. Yu, M. Liang, E. Song, M.T. Esser, N. Shire, K.E. Sherman, HBV and HIV/HBV Infected Patients Have Distinct Immune Exhaustion and Apoptotic Serum Biomarker Profiles, Pathog Immun 4(1) (2019) 39-65.

[129] E.J. Jun, J.Y. Han, H.S. Sun, [Clinical significances of serum soluble fas and soluble fas ligand in chronic hepatitis B], Korean J Hepatol 12(4) (2006) 507-14.

[130] Y. Kanda, Y. Tanaka, K. Shirakawa, T. Yatomi, N. Nakamura, M. Kami, T. Saito, K. Izutsu, T. Asai, K. Yuji, S. Ogawa, H. Honda, K. Mitani, S. Chiba, Y. Yazaki, H. Hirai, Increased soluble Fas-ligand in sera of bone marrow transplant recipients with acute graft-versus-host disease, Bone Marrow Transplant 22(8) (1998) 751-4.

[131] H. Zheng, G. Du, R. Zhao, B. Tang, N. Zhu, Enhanced allogeneic skin-graft survival using sCD95L, sCD152, interleukin-10 and transforming growth factor-beta in combination, and comparison with ciclosporin, Clin Exp Dermatol 34(6) (2009) 721-7.

[132] J.R. Muppidi, R.M. Siegel, Ligand-independent redistribution of Fas (CD95) into lipid rafts mediates clonotypic T cell death, Nat Immunol 5(2) (2004) 182-9.

[133] R.W. Georgantas, 3rd, O. Bohana-Kashtan, C.I. Civin, Ex vivo soluble fas ligand treatment of donor cells to selectively reduce murine acute graft versus host disease, Transplantation 82(4) (2006) 471-8.

[134] C.A. Klebanoff, C.D. Scott, A.J. Leonardi, T.N. Yamamoto, A.C. Cruz, C. Ouyang, M. Ramaswamy, R. Roychoudhuri, Y. Ji, R.L. Eil, M. Sukumar, J.G. Crompton, D.C. Palmer, Z.A. Borman, D. Clever, S.K. Thomas, S. Patel, Z. Yu, P. Muranski, H. Liu, E. Wang, F.M. Marincola, A. Gros, L. Gattinoni, S.A. Rosenberg, R.M. Siegel, N.P. Restifo, Memory T cell-driven differentiation of naive cells impairs adoptive immunotherapy, J Clin Invest 126(1) (2016) 318-34.

[135] M. Goto, Elevation of soluble Fas (APO-1, CD95) ligand in natural aging and Werner syndrome, Biosci Trends 2(3) (2008) 124-7. 
[136] R.M. Pitti, S.A. Marsters, D.A. Lawrence, M. Roy, F.C. Kischkel, P. Dowd, A. Huang, C.J. Donahue, S.W. Sherwood, D.T. Baldwin, P.J. Godowski, W.I. Wood, A.L. Gurney, K.J. Hillan, R.L. Cohen, A.D. Goddard, D. Botstein, A. Ashkenazi, Genomic amplification of a decoy receptor for Fas ligand in lung and colon cancer, Nature 396(6712) (1998) 699-703. [137] C. Bai, B. Connolly, M.L. Metzker, C.A. Hilliard, X. Liu, V. Sandig, A. Soderman, S.M. Galloway, Q. Liu, C.P. Austin, C.T. Caskey, Overexpression of M68/DcR3 in human gastrointestinal tract tumors independent of gene amplification and its location in a fourgene cluster, Proc Natl Acad Sci U S A 97(3) (2000) 1230-5.

[138] S. Tsuji, R. Hosotani, S. Yonehara, T. Masui, S.S. Tulachan, S. Nakajima, H. Kobayashi, M. Koizumi, E. Toyoda, D. Ito, K. Kami, T. Mori, K. Fujimoto, R. Doi, M. Imamura, Endogenous decoy receptor 3 blocks the growth inhibition signals mediated by Fas ligand in human pancreatic adenocarcinoma, Int J Cancer 106(1) (2003) 17-25.

[139] I. Cascino, G. Papoff, A. Eramo, G. Ruberti, Soluble Fas/Apo-1 splicing variants and apoptosis, Frontiers in bioscience : a journal and virtual library 1 (1996) d12-8.

[140] A. Tomokuni, T. Aikoh, T. Matsuki, Y. Isozaki, T. Otsuki, S. Kita, H. Ueki, M. Kusaka, T. Kishimoto, A. Ueki, Elevated soluble Fas/APO-1 (CD95) levels in silicosis patients without clinical symptoms of autoimmune diseases or malignant tumours, Clin Exp Immunol 110(2) (1997) 303-9.

[141] I. Cascino, G. Fiucci, G. Papoff, G. Ruberti, Three functional soluble forms of the human apoptosis-inducing Fas molecule are produced by alternative splicing, J Immunol 154(6) (1995) 2706-13.

[142] J. Cheng, T. Zhou, C. Liu, J.P. Shapiro, M.J. Brauer, M.C. Kiefer, P.J. Barr, J.D. Mountz, Protection from Fas-mediated apoptosis by a soluble form of the Fas molecule, Science 263(5154) (1994) 1759-62.

[143] O.V. Proussakova, N.A. Rabaya, A.B. Moshnikova, E.S. Telegina, A. Turanov, M.G. Nanazashvili, I.P. Beletsky, Oligomerization of soluble Fas antigen induces its cytotoxicity, J Biol Chem 278(38) (2003) 36236-41.

[144] T.G. Bivona, H. Hieronymus, J. Parker, K. Chang, M. Taron, R. Rosell, P. Moonsamy, K. Dahlman, V.A. Miller, C. Costa, G. Hannon, C.L. Sawyers, FAS and NF-kappaB signalling modulate dependence of lung cancers on mutant EGFR, Nature 471(7339) (2011) 523-6. [145] A.S. Qadir, J.P. Guégan, C. Ginestier, A. Chaibi, A. Bessede, E. Charafe-Jauffret, M. Macario, V. Lavoué, T. de la Motte Rouge, C. Law, J. Vilker, H. Wang, E. Stroup, M.J. Schipma, B. Bridgeman, A.E. Murmann, Z. Ji, P. Legembre, M.E. Peter, Tumor expressed CD95 causes suppression of anti-tumor activity of NK cells in a model of triple negative breast cancer, bioRxiv (2021) 2021.02.12.431011.

[146] J.B. Oliveira, J.J. Bleesing, U. Dianzani, T.A. Fleisher, E.S. Jaffe, M.J. Lenardo, F. RieuxLaucat, R.M. Siegel, H.C. Su, D.T. Teachey, V.K. Rao, Revised diagnostic criteria and classification for the autoimmune lymphoproliferative syndrome (ALPS): report from the 2009 NIH International Workshop, Blood 116(14) (2010) e35-40.

[147] J.L. Chu, J. Drappa, A. Parnassa, K.B. Elkon, The defect in Fas mRNA expression in $\mathrm{MRL} / \mathrm{lpr}$ mice is associated with insertion of the retrotransposon, ETn, J Exp Med 178(2) (1993) 723-30.

[148] M. Adachi, R. Watanabe-Fukunaga, S. Nagata, Aberrant transcription caused by the insertion of an early transposable element in an intron of the Fas antigen gene of Ipr mice, Proc Natl Acad Sci U S A 90(5) (1993) 1756-60. 
[149] G. Eisele, P. Roth, K. Hasenbach, S. Aulwurm, F. Wolpert, G. Tabatabai, W. Wick, M. Weller, APO010, a synthetic hexameric CD95 ligand, induces human glioma cell death in vitro and in vivo, Neuro Oncol 13(2) (2011) 155-64.

[150] C. Zou, J. Ma, X. Wang, L. Guo, Z. Zhu, J. Stoops, A.E. Eaker, C.J. Johnson, S. Strom, G.K. Michalopoulos, M.C. DeFrances, R. Zarnegar, Lack of Fas antagonism by Met in human fatty liver disease, Nat Med 13(9) (2007) 1078-85.

[151] J. Xiao, J. Yao, L. Jia, C. Lin, D.N. Zacks, Protective Effect of Met12, a Small Peptide Inhibitor of Fas, on the Retinal Pigment Epithelium and Photoreceptor After Sodium lodate Injury, Invest Ophthalmol Vis Sci 58(3) (2017) 1801-1810.

[152] W. Wick, H. Fricke, K. Junge, G. Kobyakov, T. Martens, O. Heese, B. Wiestler, M.G. Schliesser, A. von Deimling, J. Pichler, E. Vetlova, I. Harting, J. Debus, C. Hartmann, C. Kunz, M. Platten, M. Bendszus, S.E. Combs, A phase II, randomized, study of weekly APG101+reirradiation versus reirradiation in progressive glioblastoma, Clin Cancer Res 20(24) (2014) 6304-13. 
Ethics approval and consent to participate

'Not applicable'

\section{Consent for publication}

'Not applicable'

\section{Availability of data and material}

'Not applicable'

\section{Competing interests}

M.J., P.V., P.B. and P.L. have filled patents covering drugs targeting CD95/CD95L in inflammatory disorders (WO2014118317, WO2015189236, WO2015158810, WO2015104284, WO2017149012, WO2018130679).

\section{Funding}

This work was supported by INCa PLBIO (PLBIO 2018-132), Ligue Contre le Cancer, Fondation ARC, Fondation de France (Price Jean Valade), and ANR PRCE (ANR-17-CE150027).

\section{Authors' contributions}

K.K., A.B-M, G.G, M.J., P.V., P.B. and P.L. combined data and wrote the manuscript

\section{Acknowledgements}

We acknowledge support from INCa PLBIO (PLBIO 2018-132), Ligue Contre le Cancer, Fondation ARC, Fondation de France (Price Jean Valade), and ANR PRCE (ANR-17-CE150027). 


\section{Figure Legends.}

Figure 1. CD95 from gene to protein.

Schematic diagram illustrating gene localization of CD95 (Fas) on human chromosome 10 and its mRNA and protein structures.

Figure 2. CD95L from gene to protein.

Schematic diagram illustrating gene localisation of CD95L (FasL) on human chromosome 1, and its mRNA and protein structures. Tumor Necrosis Factor; TNF.

\section{Figure 3. CD95-mediated signaling pathways.}

Left panel: Binding of m-CD95L to CD95 leads to the recruitment of the adaptor protein FADD (Fas-associated protein with death domain) through the death domain (DD) of CD95. This leads to the formation of the death inducing signaling complex (DISC) resulting in the induction of apoptosis. Right panel: CD95L can be cleaved by MMP (Metalloprotease) to release a soluble ligand (s-CD95L). s-CD95L binds CD95, which in turn recruits PLC $\gamma 1$ (Phospholipase $\mathrm{C}$ gamma 1) via its calcium-inducing domain (CID). Plasma membrane recruitment of PLC $\gamma 1$ triggers the generation of inositol 1,4,5-trisphosphate (IP3) and diacylglycerol (DAG). IP3 binds to its receptors (IP3Rs) at the endoplasmic reticulum (ER) to release $\mathrm{Ca}^{2+}$ (calcium) from the ER, leading to the redistribution of calcium sensor STIM1 to the plasma membrane where it activates an ORAI1 channel-driven entry of extracellular calcium. This accumulation of calcium combined with the production of DAG activates PKC $\beta 2$, which inhibits FADD recruitment and DISC formation. This s-CD95L-mediated signal promotes the formation of a Motility inducing signaling complex (MISC) containing among others, NADPH oxidase (Nox)3 and c-yes in triple negative breast cancer cells (TNBC).

\section{Figure 4: Deregulation of $\mathrm{s}-\mathrm{CD} 95 \mathrm{~L}$ expression in cancers.}

A. The concentration of s-CD95L correlates with poor prognosis in lymphoma, multiplemyeloma, melanoma, colon cancer, pancreatic cancer, stomach cancer, Ewing's cancer, breast cancer, liver cancer, uterine cancer, prostate cancer and ocular tumors.

B. s-CD95L concentration correlates with poor prognosis in thyroid cancer and ovarian cancer.

C. No variation of s-CD95L was detected in patients affected by lung cancer and head and neck cancer as compared to healthy subjects. 


\section{Declaration of Interests}

M.J., P.V., P.B. and P.L. have filled patents covering drugs targeting CD95/CD95L in inflammatory disorders (WO2014118317, WO2015189236, WO2015158810, WO2015104284, WO2017149012, WO2018130679). 
Keerthi Kurma, writing, review \& editing.

Andrea Boizard-Moracchini, review \& editing.

Gael Galli, review \& editing.

Mickael Jean, review \& editing.

Pierre Vacher, writing, review \& editing. Funding acquisition

Patrick Blanco, writing, review \& editing. Funding acquisition

Patrick Legembre writing, review \& editing. Funding acquisition 


\section{CD95}
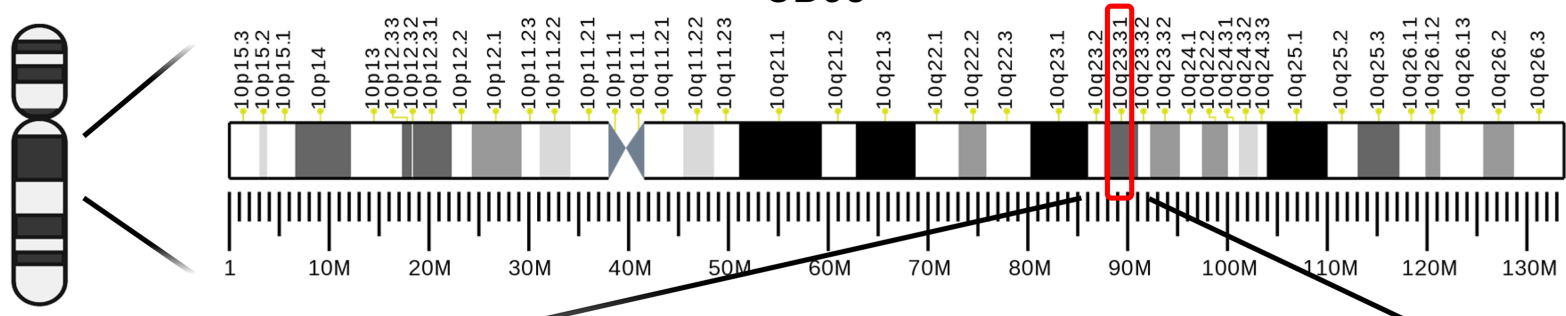

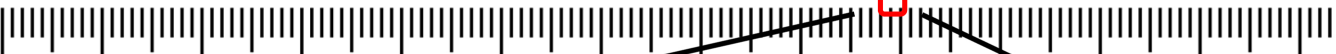

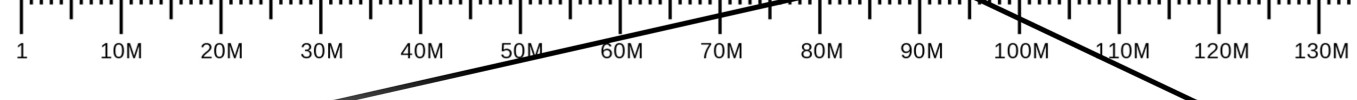

Chromosome 10
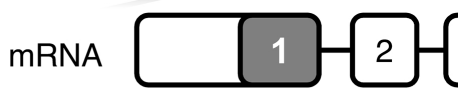

3

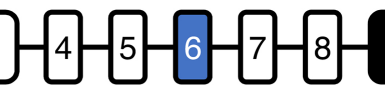

9

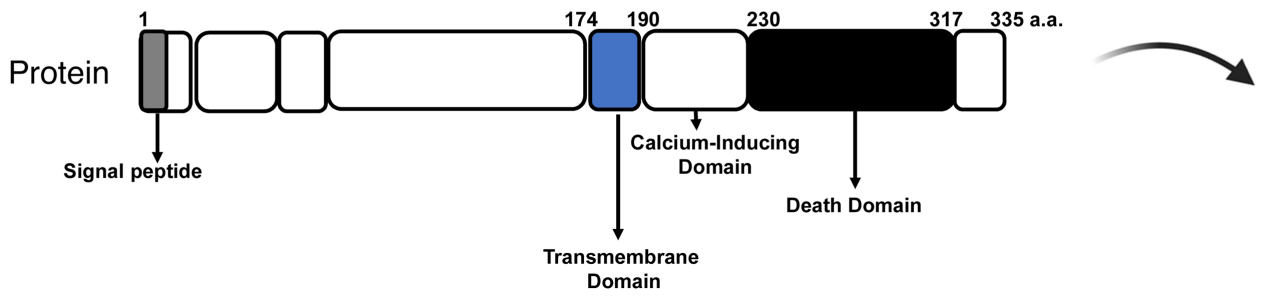

CD95

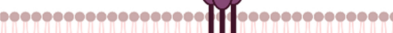




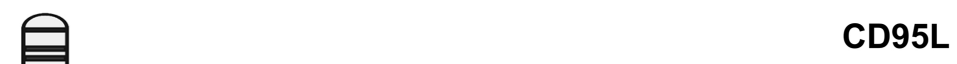

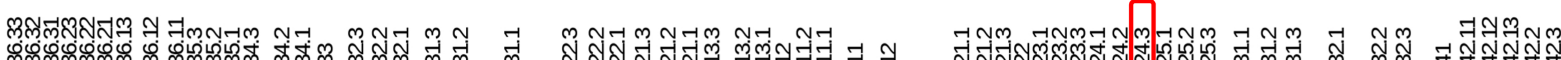

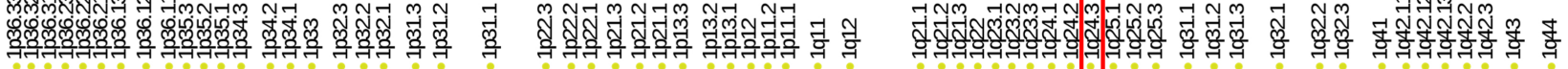

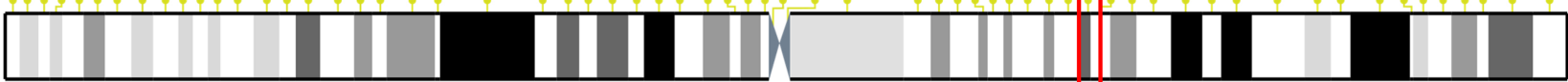

帮

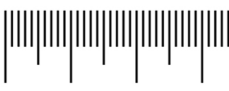

Chromosome 1

mRNA

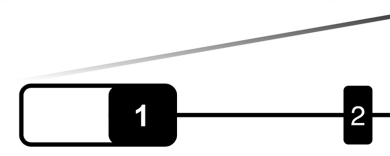

$90 \mathrm{M}$
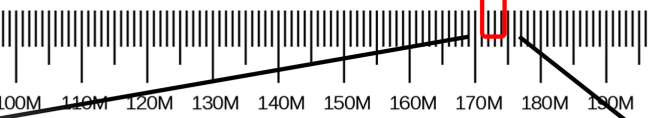

|| || || |||||||||||||||||||||||||||||||||||||||||||||||||||

$200 \mathrm{M} 210 \mathrm{M} 220 \mathrm{M} 230 \mathrm{M} 240 \mathrm{M}$

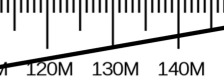

OM $160 \mathrm{M}$

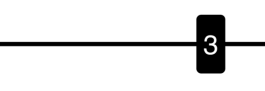

4
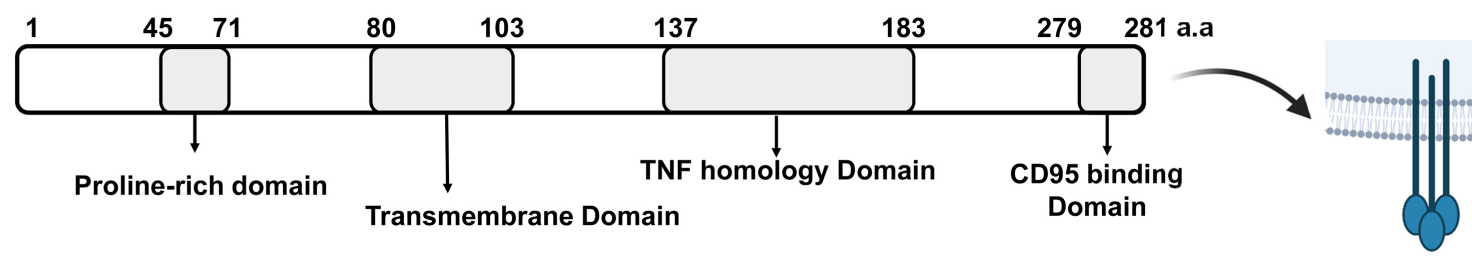

CD95L

Figure 2 


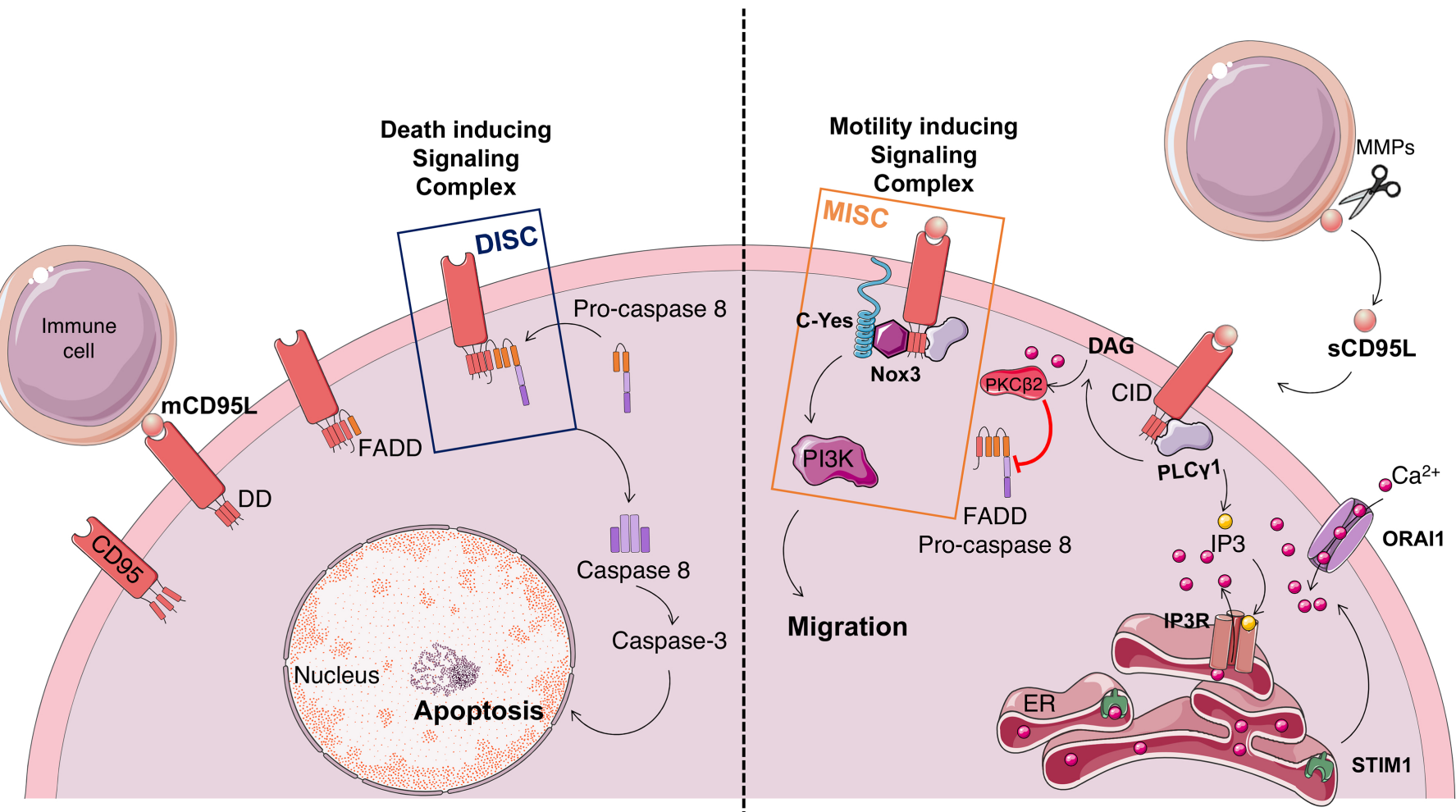

Figure 3 

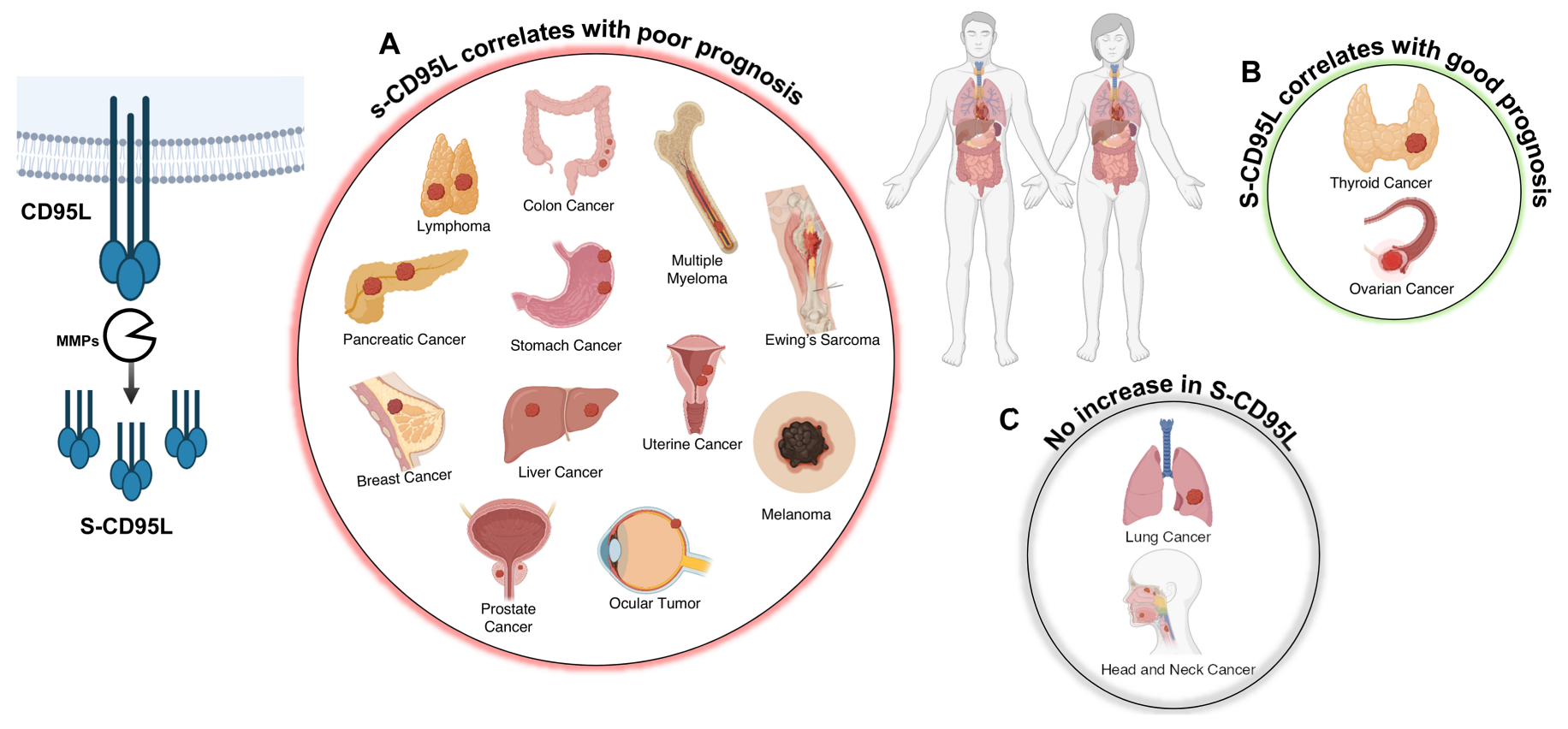

Figure 4 